\title{
Endoscopy in Pediatric Inflammatory Bowel Disease: A Position Paper on Behalf of the Porto IBD Group of the European Society for Pediatric Gastroenterology, Hepatology and Nutrition
}

Oliva, Salvatore ; Thomson, Mike ; de Ridder, Lissy ; Martín-de-Carpi, Javier ; Van Biervliet, Stephanie ; Braegger, Christian ; Dias, Jorge Amil ; Kolacek, Sanja ; Miele, Erasmo ; Buderus, Stephan ; Bronsky, Jiri ; Winter, Harland ; Navas-López, Víctor Manuel ; Assa, Amit ; Chong, Sonny K F ; Afzal, Nadeem

Ahmad ; Smets, Francoise ; Shaoul, Ron ; Hussey, Séamus ; Turner, Dan ; Cucchiara, Salvatore

\begin{abstract}
Endoscopy is a central tool for the evaluation and management of inflammatory bowel disease (IBD). In the last few decades, gastrointestinal (GI) endoscopy has undergone significant technological developments including availability of pediatric-size equipment, enabling comprehensive investigation of the GI tract in children. Simultaneously, professional organization of GI experts have developed guidelines and training programs in pediatric GI endoscopy. This prompted the Porto Group on Pediatric IBD of the European Society for Pediatric Gastroenterology, Hepatology and Nutrition to develop updated guidelines on the role of GI endoscopy in pediatric IBD, specifically taking into considerations of recent advances in the diagnosis, disease stratification, and novel therapeutic targets in these patients.
\end{abstract}

DOI: https://doi.org/10.1097/MPG.0000000000002092

Posted at the Zurich Open Repository and Archive, University of Zurich

ZORA URL: https://doi.org/10.5167/uzh-165366

Journal Article

Published Version

Originally published at:

Oliva, Salvatore; Thomson, Mike; de Ridder, Lissy; Martín-de-Carpi, Javier; Van Biervliet, Stephanie; Braegger, Christian; Dias, Jorge Amil; Kolacek, Sanja; Miele, Erasmo; Buderus, Stephan; Bronsky, Jiri; Winter, Harland; Navas-López, Víctor Manuel; Assa, Amit; Chong, Sonny K F; Afzal, Nadeem Ahmad; Smets, Francoise; Shaoul, Ron; Hussey, Séamus; Turner, Dan; Cucchiara, Salvatore (2018). Endoscopy in Pediatric Inflammatory Bowel Disease: A Position Paper on Behalf of the Porto IBD Group of the European Society for Pediatric Gastroenterology, Hepatology and Nutrition. Journal of Pediatric Gastroenterology and Nutrition, 67(3):414-430.

DOI: https://doi.org/10.1097/MPG.0000000000002092 


\title{
Endoscopy in Pediatric Inflammatory Bowel Disease: A Position Paper on Behalf of the Porto IBD Group of the European Society for Pediatric Gastroenterology, Hepatology and Nutrition
}

\author{
${ }^{*}$ Salvatore Oliva, ${ }^{\dagger}$ Mike Thomson, ${ }^{\ddagger}$ Lissy de Ridder, ${ }^{\S}$ Javier Martin-de-Carpi, \\ "Stephanie Van Biervliet, "Christian Braegger, ${ }^{\#}$ Jorge Amil Dias, ${ }^{* *}$ Sanja Kolacek, \\ ${ }^{\dagger \dagger}$ Erasmo Miele, ${ }^{\ddagger \dagger}$ Stephan Buderus, ${ }^{\S}$ Jiri Bronsky, ${ }^{\prime \prime I}$ Harland Winter, \\ "Víctor Manuel Navas-López, ${ }^{\# \#}$ Amit Assa, ${ }^{* * *}$ Sonny K.F. Chong, \\ ${ }^{\dagger \dagger \dagger}$ Nadeem Ahmad Afzal, ${ }^{\ddagger \ddagger \ddagger}$ Francoise Smets, ${ }^{\S \S \S}$ Ron Shaoul, ,IIIIIIII Séamus Hussey, \\ ${ }^{\top}$ "Dan Turner, and ${ }^{*}$ Salvatore Cucchiara
}

\begin{abstract}
Endoscopy is a central tool for the evaluation and management of inflammatory bowel disease (IBD). In the last few decades, gastrointestinal (GI) endoscopy has undergone significant technological developments including availability of pediatric-size equipment, enabling comprehensive investigation of the GI tract in children. Simultaneously, professional organization of GI experts have developed guidelines and training programs in pediatric GI endoscopy. This prompted the Porto Group on Pediatric IBD of the European Society for Pediatric Gastroenterology, Hepatology and Nutrition to develop updated guidelines on the role of GI endoscopy in pediatric IBD, specifically taking into considerations of recent advances in the diagnosis, disease stratification, and novel therapeutic targets in these patients.
\end{abstract}

Key Words: children, endoscopy, inflammatory bowel disease, pediatrics

(JPGN 2018;67: 414-430)

\section{INTRODUCTION}

E ndoscopy is a central tool for the evaluation and management of inflammatory bowel disease (IBD). In the last few decades, gastrointestinal (GI) endoscopy has undergone significant advances and adaptation for application in pediatric patients, facilitating comprehensive investigation of the GI tract in infants and children. Simultaneously, scientific organizations have developed guidelines and training programs in pediatric GI endoscopy (1).

There are currently no specific pediatric IBD (PIBD) endoscopy guidelines, although recently published European Society for Pediatric Gastroenterology, Hepatology and Nutrition (ESPGHAN) Pediatric Endoscopy Guidelines refer to the subject matter (1). This prompted the Porto Group on Pediatric IBD of the European Society for Pediatric Gastroenterology, Hepatology and Nutrition (ESPGHAN) to develop a position paper on the role of GI endoscopy in PIBD, specifically taking into consideration recent advances in

NHS Trust, Carshalton, Surrey, the †††Department of Paediatric Gastroenterology, University Hospital Southampton, Southampton, UK, the ¥¥Pediatric Gastroenterology and Hepatology Unit, IREC, Cliniques Universitaires Saint-Luc, Université Catholique de Louvain, Brussels, Belgium, the $\S \S \S$ Rambam Medical Center, Haifa, Israel, the ||||||||||National Children's Research Centre and Royal College of Surgeons of Ireland, Dublin, Ireland, and the $\uparrow \uparrow$ Institute of Paediatric Gastroenterology, Hebrew University of Jerusalem, Jerusalem, Israel.

Address correspondence and reprint requests to Salvatore Oliva, MD, Department of Pediatrics, Pediatric Gastroenterology and Liver Unit, Sapienza University of Rome, Viale Regina Elena 324, 00161 Roma, Italy (e-mail: salvatore.oliva@uniroma1.it).

Disclaimer: ESPGHAN is not responsible for the practices of physicians and provides guidelines and position papers as indicators of best practice only. Diagnosis and treatment is at the discretion of physicians.

The authors report no conflicts of interest.

Copyright $(\mathcal{2} 2018$ by European Society for Pediatric Gastroenterology, Hepatology, and Nutrition and North American Society for Pediatric Gastroenterology, Hepatology, and Nutrition

DOI: 10.1097/MPG.0000000000002092 
PIBD pertaining to diagnosis, disease stratifications and emerging therapeutic targets.

\section{METHODS}

\section{Scope and Purpose}

The Pediatric IBD Porto Group of ESPGHAN developed guidelines on diagnostic approach to PIBD in 2014 (2). As endoscopy was only considered in the context of the diagnostic workup, the Porto Group set out to develop PIBD-specific endoscopy position paper following review the current literature.

\section{Literature Review}

An initial systematic literature search was conducted using PubMed, Medline, Embase, Cochrane Library, and Scopus databases until November 2015 using the following MESH terms (("Adolescent" [Mesh] OR "Child" [Mesh] OR "Infant" [Mesh] OR "Minors" [Mesh] or "Pediatrics" [Mesh]) AND ("Endoscopy" [Mesh] OR "endoscope" [Mesh] OR "videoendoscopy" [Mesh] OR "Endoscopy, Digestive System" [Mesh]) AND ("Inflammatory Bowel Diseases"[Mesh] OR "Enteritis"[Mesh] OR "Colitis"[Mesh] OR "Ileitis" [Mesh] OR "Crohn disease" [Mesh] OR "Proctitis"[Mesh]). Studies were restricted to humans and non-English publications were excluded.

\section{Review, Grading of Evidence, and Consensus Process}

Two members of the Porto Group (L.d.R. and S.C.) identified the following main topics: diagnosis; endoscopic monitoring; small bowel (SB) endoscopy; therapeutic endoscopy; and surveillance.

An open call for participants for the project occurred among Porto Group members, Porto interest group and ESPGHAN members. Contributors were selected by a steering committee (S.C., L.d.R., D.T., M.T., S.O.) on the basis of a statement, their personal curriculum vitae and publications. The selected consensus group included pediatric gastroenterologists and endoscopists expert in the field of IBD.

Each topic had a working group (WG), a Chair and different participants. Each WG performed an extensive literature search on the assigned topic by using appropriate keywords through Medline/ PubMed/ISI/Scopus and the Cochrane database in November 2015. All the available studies until November 2015 were included. A second search and update of the evidence was performed after the authors' voting process in September 2017. Finally, new relevant references were also included at the end of the peer-review revision process in December 2017.

The working parties then met twice in 2015 (Amsterdam and Barcelona) and once in 2016 (in Porto) to revise and develop agreement with the statements. Each statement was revised until consensus was reached. The panel then voted on all recommendations and practice points, while adding specific comments using a web-based voting platform. The document was revised again based on comments received. A second round of electronic voting and revisions was done, including the entire members of the Pediatric IBD group of ESPGHAN.

The Consensus Statement was reached at $>80 \%$ participant agreement.

For each statement, the level of evidence (EL) and the grading of recommendations (RG) were given according to the Oxford Centre for Evidence Based Medicine 2011 (Table 1, https:// www.cebm.net/2011/06/explanation-2011-ocebm-levels-evidence).

\section{MANUSCRIPT}

Each WG provided a summary of written background evidence for statements to draft the initial manuscript by S.O. and S.C. The manuscript was circulated to the consensus group for revisions and to the Porto IBD Group of ESPGHAN before submission for publication. The final text was edited for consistency of style by S.C., D.T., and S.O., for approval by the journal and ESPGHAN council.

\section{Recommendations}

Table 2 provides a synopsis of the recommendations.

The Position Paper includes not only recommendations but also "practice points" that reflect common practice wherein evidence is lacking. Weaker recommendations are indicated by phrases such as "we suggest," whereas stronger recommendations are typically stated as "we recommend." Recommendations are intended to be read in context with the qualifying comments in the accompanying text.

\section{Recommendations:}

\section{DIAGNOSIS}

1. In non-emergency situations, the diagnostic evaluation for suspected IBD in children should include a combination of esophagogastroduodenoscopy (EGD) and ileocolonoscopy (IC) [EL4, RGC]. (97\% agreement)

2. During IC and EGD, multiple biopsies $(\geq 2)$ should be obtained from each segment even in the absence of macroscopic lesions [EL4, RGC]. (90\% agreement)

\section{Practice points:}

(1) Pediatric Endoscopy should be performed by a pediatric gastroenterologist, or in some cases, by a gastroenterologist with specific pediatric training and/or supported by a pediatric team in a pediatric-friendly setting, as described in the recent ESPGHAN/European Society for Gastrointestinal Endoscopy (ESGE) guidelines (1).

(2) According to the revised Porto Criteria, endoscopy is usually recommended in the presence of alarming symptoms (ie, bloody diarrhea, weight loss, abdominal pain) and/or positive serum inflammatory markers (C-CRP) an/or ESR), and/or high levels of fecal calprotectin.

(3) It is recommended to collect 2 biopsies samples from duodenum, stomach and esophagus during EGD, and from terminal ileum, cecum, transverse colon, sigmoid colon, and rectum during IC.

(4) In severe acute colitis, a limited sigmoidoscopy may be safer than doing a complete colonoscopy. A follow-up colonoscopy should be performed after the resolution of an acute attack; however, in experienced hands, total colonoscopy can often safely be completed even during acute attacks.

Endoscopy remains the fundamental diagnostic tool for IBD in both adults and children. IC should include complete colonoscopy with ileal intubation $(1,2)$. Indeed, colonic involvement is more frequent in pediatric Crohn disease (CD) than in adult(s), and the diagnosis cannot be based exclusively on sigmoidoscopy or partial colonoscopy, as ileal intubation can suggest or confirm CD diagnosis (3). Unfortunately, failure to visualize the terminal ileum is reported in around $20 \%$ to $25 \%$ of pediatric cases (4). For this reason, it is crucial that endoscopy for pediatric IBD should be performed by pediatric or adult gastroenterologists with adequate training (1). Endoscopy is usually recommended when alarm 


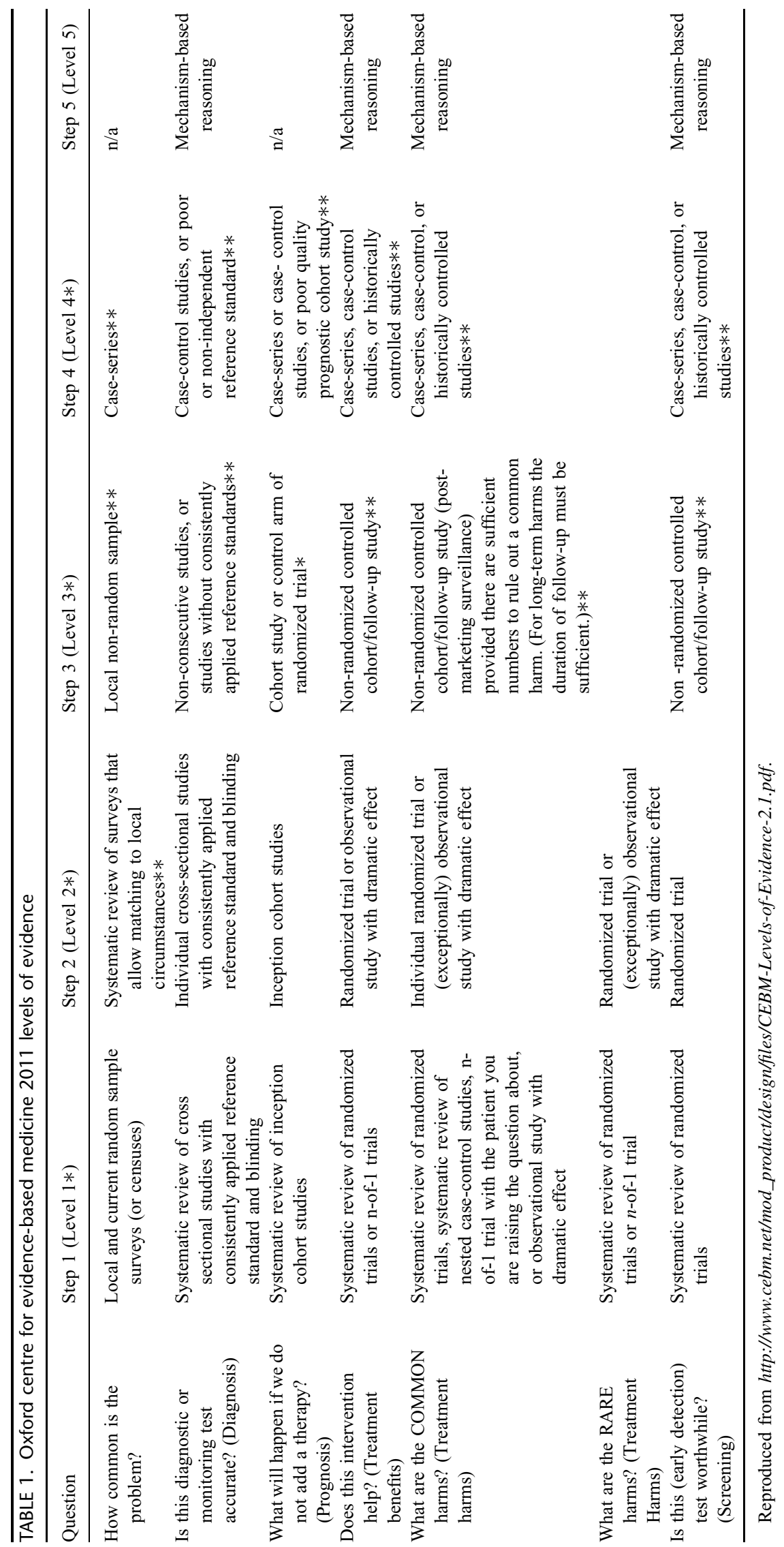


TABLE 2. Guideline recommendations

1. In non-emergency situations, the diagnostic evaluation for suspected IBD in children should include a combination of esophagogastroduodenoscopy (EGD) and ileocolonoscopy (IC).

2. During IC and EGD, multiple biopsies $(\geq 2)$ should be obtained from each segment even in the absence of macroscopic lesions.

3. Endoscopic evaluation of the intestinal mucosa is recommended in the following circumstances:

Before major treatment changes (escalating or de-escalating).

In symptomatic patients when it is not clear whether the symptoms are inflammation-related, such as when IBS is suspected to account for symptoms. In $\mathrm{CD}$ to ensure mucosal healing during clinical remission.

In UC to ensure mucosal healing during clinical remission only if fecal calprotectin is elevated.

4. Following bowel resection, endoscopic evaluation should be performed 6-12 months later, aiming to identify postoperative recurrence.

5. Pouchoscopy is indicated to confirm suspected diagnosis of pouchitis, especially at the first episode.

6. Determining endoscopic activity with validated indices is recommended in clinical trials and it is suggested in clinical practice.

7. The recommended scores in adult and pediatric IBD are

The CD endoscopic index of severity (CDEIS) and/or the Simple Endoscopic Score for CD (SES-CD)

The Mayo endoscopic score or Ulcerative Colitis Endoscopic Index of Severity (UCEIS) for UC.

The Rutgeerts' score for assessing post-surgical CD recurrence in the neo-terminal ileum.

8. CE is complementary to MRE for evaluating SB inflammation. In suspected CD, either CE or MRE are recommended.

9. In established CD, MRE may precede or be preferred to CE, especially with risk of stenosis.

10. In the presence of high clinical suspicion for $\mathrm{CD}$ without stenosis, $\mathrm{CE}$ should be considered even after a negative magnetic resonance enterography, due to the higher sensitivity for mucosal lesions.

11. Before performing CE, intestinal stricture or narrowing must be excluded, as capsule retention is the most relevant side effect of the procedure, although it rarely causes any clinical sequelae.

12. The use of endoscopic disease activity scores is suggested to facilitate prospective SB CE follow-up and to evaluate response to medical therapy.

13. If intestinal stenosis is suspected or a biopsy is needed due to uncertain CE results, push or balloon-assisted enteroscopy is suggested.

14. Endoscopic balloon dilation is recommended in short $(\leq 4 \mathrm{~cm})$ and reachable strictures.

15. A surveillance program is suggested in pediatric UC after 10 years from the onset of disease. Surveillance may start as early as 8 years in older children ( $>16$ years) if any of the following risk factors are present: extensive colitis; high burden of the colitis over time (a factor of severity and chronicity); and family history of colorectal cancer in a first-degree relative at $<50$ years.

16. In IBD cases with concurrent primary sclerosing cholangitis (PSC), surveillance IC may be considered annually or at least bi-annually, starting from the time of PSC diagnosis or shortly thereafter. However, in children $<12$ years of age, surveillance could be postponed depending on to the presence of individual risk factors (disease duration, family history, severity of the disease over time and disease extent).

17. The endoscopic procedure for surveillance examination should be performed in a quiescent period of the disease to minimize false positive interpretation of dysplasia.

$\mathrm{CD}=$ Crohn disease $\mathrm{CE}=$ caspule endoscopy $\mathrm{EGD}=$ esophagogastroduodenoscopy $; \mathrm{IBD}=$ inflammatory bowel disease $; \mathrm{IC}=\mathrm{ileocolonoscopy} ; \mathrm{MRE}=$ magnetic resonance enterography; $\mathrm{SB}=$ small bowel; $\mathrm{UC}=$ ulcerative colits.

symptoms or signs, positive blood markers, and/or high levels of fecal calprotectin are present (2). In a recent meta-analysis, fecal calprotectin added the most diagnostic value to symptoms compared with commonly used blood markers. Fecal calprotectin should precede endoscopy in the diagnostic evaluation of referred pediatric patients with symptoms suggestive of IBD, since its higher fecal calprotectin levels considerably increases the likelihood to find inflammatory lesions (5). Endoscopy of the ileo-colon should be deferred in cases of toxic megacolon, while in cases of acute severe colitis, sigmoidoscopy or partial/full IC may be considered in expert hands. The Porto Criteria and ESPGHAN Paediatric Endoscopy Guidelines, based on strong evidence-based data, that EGD should be performed in all children at the initial evaluation of disease irrespective of the presence or absence of upper gastrointestinal symptoms (2). Absence of specific upper gastrointestinal symptoms does not preclude presence of upper gastrointestinal inflammation. In a retrospective study of 172 children with suspected IBD, the diagnosis was changed to CD based on biopsies obtained at EGD (6). Data from the PIBD registry found that EGD helped to establish the final diagnosis in $10 \%$ of the children with IBD (7).

Endoscopic procedures in children should be performed according to recent ESPGHAN/ESGE recommendations, including in a pediatric-friendly setting (1). As stated in the ECCO guidelines for histopathology in IBD, multiple biopsies from at least 4 sites along the colon (cecum, transverse colon, sigmoid colon, rectum) and the terminal ileum should be obtained and placed immediately into separate vials, and should be accompanied by pertinent clinical information (8). Multiple biopsies entail a minimum of 2 representative samples from each segment including macroscopically normal segments. The Porto criteria also advocate multiple biopsies from the esophagus, stomach, and duodenum for all children with IBD irrespective of upper symptoms (2).

Establishing a definite and accurate diagnosis in a patient suspected of having IBD is mandatory. Therefore, complete evaluation should be advocated. In patients transferred to a pediatric IBD Unit without previously fulfilling Porto Criteria properly, a future strategy to complete the diagnostic workup should be planned, especially when a full IC has not been performed. If successful treatment has been adequately initiated after the first endoscopy, complete fulfillment of the Porto Criteria could be postponed. Endoscopic findings can change over short periods of time. When a colonoscopy has shown only non-specific findings, due to interruption or dissociation between endoscopy and histology, a new endoscopy should be performed to better characterize the disease.

\section{ENDOSCOPIC MONITORING}

\section{Recommendations:}

(1) Endoscopic evaluation of the intestinal mucosa is recommended in the following circumstances (EL3; RGC). (85\% agreement) 
- Before major treatment changes (escalating or de-escalating) (EL2; RGB).

- In symptomatic patients when it is not clear whether the symptoms are inflammation-related, such as when IBS is suspected to account for symptoms (EL3; RGC).

- In $\mathrm{CD}$ to ensure mucosal healing (MH) during clinical remission (EL4; RGC).

- In UC to ensure MH during clinical remission only if fecal calprotectin is elevated (EL3; RGC).

(2) Following bowel resection, endoscopic evaluation should be performed 6 to 12 months later, aiming to identify postoperative recurrence (adult EL3; RGC). (92\% agreement)

(3) Pouchoscopy is indicated to confirm suspected diagnosis of pouchitis, especially at the first episode (EL3; RGC). (87\% agreement)

(4) Determining endoscopic activity with validated indices is recommended in clinical trials and it is suggested in clinical practice [adult EL2, RGC]. (90\% agreement)

(5) The recommended scores in adult and pediatric IBD are

- The CD endoscopic index of severity (CDEIS) [adult EL1] and/or the Simple Endoscopic Score for CD (SES-CD) [EL1].

- The Mayo endoscopic score or Ulcerative Colitis Endoscopic Index of Severity (UCEIS) for UC [adult EL3, RGC].

- The Rutgeerts' score for assessing post-surgical CD recurrence in the neo-terminal ileum [adult EL3]. (95\% agreement)

\section{Practice points:}

(1) It is important to report the extent and location of inflammation and whether the inflammation is continuous, the presence of erythema in each segment of the intestine; loss of vascular pattern, bleeding (contact or spontaneous), presence of erosions or ulceration (superficial or deep), and the presence of strictures or fistulas.

(2) It is key to report the degree of change of endoscopic activity since previous evaluation (ie, decreased, increased, equal).

(3) $\mathrm{MH}$ means a complete lack of inflammation (SES-CD $=0$ and Mayo/UCEIS $=0$ ), while endoscopic remission is defined by a SES-CD $\leq 2$ and a Mayo or UCEIS $\leq 1$. Endoscopic Remission is practical and a more achievable target in clinical practice; however, $\mathrm{MH}$ remains the ideal and potentially the more relevant target.

(4) Endoscopic response is defined as a decrease in CDEIS $>5$ or SES-CD $\geq 2$ for CD, while a decrease in Mayo endoscopic subscore $\geq 1$ or in UCEIS $\geq 2$ for UC. Using relative (rather than absolute) changes, endoscopic response is a decrease from baseline of at least $50 \%$.

(5) The first $\mathrm{MH}$ evaluation after a major change of therapy can be performed between 6 and 12 months in CD. High-risk CD with younger age at onset, extensive and/or severe disease, previous drug unresponsiveness, and presence of stenosing or penetrating complications can be considered for evaluation of $\mathrm{MH}$ and disease extent after 6 months.

(6) In $\mathrm{CD}$, fecal calprotectin levels could influence timing of the follow-up procedure.

(7) The MH evaluation in UC is indicated only in presence of a discrepancy between PUCAI and fecal calprotectin levels.

(8) The possible negative effects of repetitive general anesthesia (GA) should be included in the decision making process to balance the need of endoscopy with the risk of multiple GA, especially in younger children with severe disease course.

\section{When to Evaluate}

The usefulness of endoscopic reassessment should be individualized according to the disease type, severity, risk of relapse and risk of progression and in general, when a significant change in medical management is contemplated. In pediatric IBD, the overall rate of management change after endoscopy can be up to $42 \%$ of cases (9). Unfortunately, the appropriateness of periodic endoscopic reassessment after index IC has never been formally studied and its value of it is much debated, especially in pediatric UC. Treatment changes based on endoscopy are more frequent in children with CD than UC (10). Clinical judgment and Pediatric Ulcerative Colitis Activity Index (PUCAI) have been documented to be adequate for the evaluation of disease activity in pediatric patients (11). A PUCAI $<10$ has been closely associated with MH and not inferior to endoscopic evaluation in predicting clinically important outcomes (12). Moreover, fecal biomarkers are being used more recently as surrogate markers of disease activity, and fecal calprotectin levels above $100 \mu \mathrm{g} / \mathrm{g}$ correlate with mucosal inflammation on endoscopy, especially in UC (13-16). Thus, it does not seem justified to routinely recommend endoscopic assessment in pediatric $\mathrm{UC}$ solely to assess disease activity, response to treatment or at relapse.

Unfortunately, CD fecal biomarkers are unable to detect mucosal relapse with the same accuracy as for $\mathrm{UC}$, and endoscopy is often required to identify presence of inflammation (17).

Endoscopic evaluation is recommended in any case before major treatment changes (escalating and de-escalating treatment strategies), to diagnose complications (eg, stenosis, dysplasia) and to exclude other diagnoses, such as ischemia and rarely infection, such as CMV (18).

In Clostridium difficile infection, evaluation by colonoscopy may be misleading in active colitis, as typical pseudomembranes are commonly absent $(19,20)$. Moreover, full IC is not recommended in severe colitis due to increased risk for serious complications such as perforation (21), even though it may be attempted safely in expert hands (22).

In post-colectomy patients, initial clinical suspicion of pouchitis should be confirmed by endoscopic evaluation of the pouch with mucosal biopsies, since irritable pouch syndrome is can increase stool frequency and cramping despite normal pouch endoscopy and histology (23).

The benefit of postoperative endoscopy in CD has not been prospectively evaluated in children. A recent Australian study demonstrated that adults who underwent IC 6 months after surgery to decide on treatment adjustment, had considerably lower relapse 18 months after surgery (24). Extrapolation from these data in adults suggests that a similar protocol may also be indicated in pediatric patients to monitor for postoperative recurrence and treatment aimed at relapse prevention (25).

\section{How to Evaluate}

Reporting of endoscopic disease activity should always include accurate descriptors of any abnormalities in each segment (26). Due to the variability between different operators, the scoring of endoscopic disease activity is, however, becoming an important clinical endpoint in clinical trials (27-29). The distribution and severity of inflammation noted during endoscopy of children early in the course of IBD may be patchy with a pattern that is less commonly seen in adults with IBD. For this reason, scoring systems used in adults may be difficult to extrapolate to children.

Despite their limitations, the use of an endoscopic scoring system can, however, aid in reporting endoscopic findings and 
Recently, the International Organization for the Study of Inflammatory Bowel Diseases (IOIBD) (41) published a position paper defining the treatment targets and $\mathrm{MH}$ definition. For adult patients, $\mathrm{MH}$ was described as the absence of all visible ulcers (41). Although this definition is simple to apply in clinical practice, it is relatively insensitive to change and does not allow for a quantification of overall improvement or improvement beyond ulcer healing (53). For this reason, scoring systems are of critical importance in defining $\mathrm{MH}$ in clinical practice $(27-29)$. Complete $\mathrm{MH}$ is defined as a SES-CD or CDEIS and a Mayo or UCEIS of 0, while a SES-CD or CDEIS $\leq 2$ and a Mayo or UCEIS $\leq 1$ have been considered endoscopic remission in $\mathrm{CD}$ and $\mathrm{UC}$, respectively $(26,34,42)$. Nevertheless, a Rutgeerts score value of $<$ i2 is considered endoscopic remission after surgery in CD (54). Endoscopic remission is practical and a more achievable target in clinical practice; however, $\mathrm{MH}$ remains the ideal and potentially the more relevant target. Moreover, in cases where $\mathrm{MH}$ or endoscopic remission cannot be achieved, it is important to evaluate at minimum the treatment efficacy by defining the endoscopic response at least.

The IOIBD defines endoscopic response as a decrease in CDEIS $>5$ or SES-CD $\geq 2$ for CD, while a decrease in Mayo endoscopic subscore $\geq 1$ or in UCEIS $\geq 2$ for UC (55). Using relative (rather than absolute) changes, endoscopic response is a decrease of at least $50 \%$ from baseline. Indeed, a recent post hoc analysis of the SONIC trial showed that endoscopic response could be defined as a decrease of at least $50 \%$ from baseline (55).

Few studies have attempted to determine optimal timing for evaluation of $\mathrm{MH}$ in $\mathrm{CD}$ after a major change of treatment. Recently, Bouguen et al showed that shorter times between endoscopic procedures with consequent adjustments in medical therapy if ulcers were identified were associated with a higher rate of $\mathrm{MH}$ (45).

Emerging data also indicate that early $\mathrm{MH}$ may be more important than baseline disease severity or timing of drugs for predicting sustained long-term remission (47-48). Projecting these data to endoscopy, achieving $\mathrm{MH}$ early in disease is an important target that may ultimately alter the natural history of the disease. Indeed, early $\mathrm{MH}$ rather than early treatment drives improved outcome (56).

Moreover, the time frame for MH to occur while on treatment ranged from 10 to 26 weeks, with higher rates of $\mathrm{MH}$ seen at later time points from various controlled trials $(44,57,58)$. According to these data, a 26-week ( 6 month) assessment may be associated with an improved $\mathrm{MH}$ rate. The first $\mathrm{MH}$ evaluation after a major change of therapy can be performed between 6 and 12 months in CD. Risk stratification of the disease could help define the exact timing. High-risk $\mathrm{CD}$ can be defined including younger age at onset, extensive and/or severe disease, previous drug unresponsiveness, and presence of stenosing or penetrating complications $(59,60)$. After appropriate treatment patients at high risk for progression should be reassessed at 6 months for MH (59).

It is important to note that for the purpose of $\mathrm{MH}$, a risk to increase the frequency of endoscopic procedures may exist, making it likely that pediatric IBD patients will undergo multiple episodes of GA (61). Preliminary reports, mainly on animals, have suggested potential long-term negative side effects of GA applied in children (62-67), thus giving reason to pause before complying with this strategy (68-69). On the other hand, a considerable proportion of patients in clinical remission may not have $\mathrm{MH}$ and go undetected without endoscopy. A recent pediatric study demonstrates that despite being in clinical remission, up to $30 \%$ of patients with IBD revealed active disease on first endoscopy after 1 year. Leaving inflammation untreated in carries a significant risk in long-term outcomes (56). Identifying active patients and altering treatment may halt disease progression. Similar findings have been shown in a review of the SONIC data and data from clinical practice $(45,46,55)$.

\section{SMALL BOWEL ENDOSCOPY Recommendations:}

1. Capsule endoscopy (CE) is complementary to magnetic resonance enterography (MRE) for evaluating SB inflammation [EL3, RGC]. In suspected CD, either CE or MRE are recommended. [EL3, RGC]. (87\% agreement)

2. In established $\mathrm{CD}, \mathrm{MRE}$ may precede or be preferred to $\mathrm{CE}$, especially with risk of stenosis. [EL3, RGC]. (97\% agreement)

3. In the presence of high clinical suspicion for $C D$ without stenosis, CE should be considered even after a negative MRE, due to the higher sensitivity for mucosal lesions [EL3, RGC]. ( $92 \%$ agreement)

4. Before performing CE, intestinal stricture or narrowing must be excluded, as capsule retention is the most relevant side effect of the procedure, although it rarely causes any clinical sequelae. [EL3, RGC]. (95\% agreement)

5. The use of endoscopic disease activity scores is suggested to facilitate prospective SB CE follow-up and to evaluate response to medical therapy [EL4, RGC]. (82\% agreement)

6. If intestinal stenosis is suspected or a biopsy is needed due to uncertain CE results, push or balloon-assisted enteroscopy is suggested [adult EL3, pediatric EL4/RGC]. (85\% agreement)

\section{Practice points:}

1. There is no accepted protocol for preparation before CE; however, prior bowel cleansing may improve SB visualization. Protocols range from overnight fasting to standard IC bowel preparations. The protocol including low-dose PEG-solution ( $25 \mathrm{~mL} / \mathrm{kg}$ up to $1 \mathrm{~L}$ the day before) and oral simethicone (just before capsule ingestion) resulted in the best visualization score and is currently suggested.

2. CE is approved for the use in children of 2 years and older that are able to swallow the capsule. Positioning of the capsule by endoscopy under GA is usually feasible in children with a body weight of at least $8 \mathrm{~kg}$.

3. In suspected $\mathrm{CD}$, the choice to perform $\mathrm{CE}, \mathrm{MRE}$ or both, depends on local availability and expertise.

4. Strictures can be assessed before CE either by MRE, patency capsule or by a combination of these methods. When an intestinal narrowing is suspected by MRE, patency capsule should be performed before CE examination.

5. CE findings assist in directing the most effective route of enteroscopy intubation (oral vs anal) according to lesion location.

6. The use of Lewis score (LS) is suggested, since it is the most widespread and known score, which can be easily calculated by using CE software. A score $<135$ is designated normal or clinically insignificant mucosal inflammatory change, a score between 135 and 790 is mild, and a score $>790$ is moderate to severe.

7. The choice between CE or enteroscopy could also be dictated by the local availability of procedures and expertise. Nonetheless, due to its lesser invasiveness, $\mathrm{CE}$ is usually preferable in the absence of strictures.

\section{Capsule Endoscopy}

$\mathrm{CE}$ is a feasible and useful endoscopic procedure for diagnosing intestinal diseases in pediatric patients (70). IC together 
with EGD, both with biopsies, still remain the most important and defining endoscopic approach in the diagnosis and management of IBD. To properly define the diagnosis (CD vs UC vs IBDU) and disease phenotype, SB imaging is needed as described in the revised Porto criteria (3). In most patients, MRE would be the method of choice for this part of the diagnostic evaluation. CE, however, has higher sensitivity for mucosal lesions (especially in the proximal SB) and may add conclusive information in defining diagnosis or disease phenotype in case of a negative MRE (71). Conversely, it can rule out IBD due to a high negative predictive value for active SB CD. CE can detect inflammatory changes (aphthous ulcers) of the intestinal mucosa and $\mathrm{MH}$. Identification of the region of the SB cannot always be reliably determined by tracking information provided by external sensors. Furthermore, the SB CE transit time percentage may be more accurate. Pediatric studies (71-73) have shown that the findings of $\mathrm{CE}$ in $\mathrm{CD}$ patients result in therapeutic consequences in up to $75 \%$ to $92 \%$. Aloi et al, showed that sensitivity and specificity of CE, MRE and contrast enhanced SB ultrasound (SICUS) are similar (74).

Some recent adult studies have shown that $\mathrm{CE}$ may be superior to MRE, particularly for the detection of early disease and proximal SB lesions (75-77). For this reason, ESGE recommends $\mathrm{CE}$ as the initial modality for investigating the $\mathrm{SB}$ in suspected CD without obstructive symptoms or known stenosis. Conversely, in established CD, the ESGE recommends dedicated cross-sectional imaging as first step, leaving $\mathrm{CE}$ as a subsequent investigation, if deemed to influence patient management (78).

According to pediatric and adult evidence-based studies, CE can be considered complementary to MRE as it is much more sensitive for evaluating mucosal lesions, while MRE is more specific for extramural and mural findings (79). Indeed, CE can detect residual inflammation even in the presence of normal serum and fecal inflammatory markers (80). It can also confirm SB MH after commencing a new treatment (81).

The capsule is usually expelled within 2 weeks after deployment into the GI tract. Longer intervals are defined as "capsule retention." This seems to be more frequent in pediatric IBDpatients than in adults. It is reported in a mean of $2.5 \%$ of pediatric patients, up to $43 \%$ in pediatric IBD-patients with malnutrition, and in $37.5 \%$ of $\mathrm{CD}$ patients with known SB disease $(82,83)$. Possible interventions are endoscopic removal if reachable (eg, stomach or ileal pouch), high volume bowel cleansing, anti-inflammatory treatment with steroids or, in rare cases of bowel obstruction, surgical removal. Mid-SB retention if clinically important can be resolved often by double-balloon enteroscopy retrieval. Long-term retention is described, but rarely is it clinically important. Usually it is more indicative of pathology that requires definitive treatment, particularly if the patient is symptomatic. An individualized approach is advisable depending on the clinical situation of the patient.

A patency capsule is available to avoid capsule retention. The purpose of this tool is to prevent capsule retention by pre-using a "capsule-dummy" that dissolves via its 2 open ends and thus be "crushed" and expelled by intestinal motility in the case of delayed passage. Its presence in the intestine can either be detected by a special radiofrequency device or x-ray.

Strictures can be assessed before CE either by MRE, patency capsule or by a combination of these methods. Although findings of small-bowel stenosis at MRE may preclude subsequent CE in $27 \%$ to $40 \%$ of patients with known CD (84), not all strictures actually result in significant mechanical obstruction and the use of the patency capsule may help to identify patients who are at increased risk of capsule retention $(85,86)$.
A recent adult study shows that MRE has a high negative predictive value and sensitivity for patency capsule retention. When capsule retention is suggested by MRE, patency capsule should be performed before the CE examination. The maximal stricture length $(>10 \mathrm{~cm})$ and the number of pre-stenotic dilations were found to be the most predictive imaging features for patency capsule retention (87).

CE is approved for children 2 years and older. Nevertheless, case series report successful use in children with a minimal age of 8 months or a minimal weight of $7.9 \mathrm{~kg}$ (88). Swallowing the capsule can be achieved by most children (89). In the majority of younger children, an application device is needed to front load the capsule to the endoscope releasing it directly into the duodenum. Mean SB transit times are reported in the range between 175 mins to 401 mins (82).

No generally accepted pre-CE protocol exists at this time. CE manufacturers did not recommend pre-procedure purgative use for $\mathrm{CE}$. The recommended requirements were only a low fiber diet with clear liquids and a 12-hour fast on the day before. Over the last few years, different randomized controlled studies have addressed the question of whether purgatives improve mucosal visibility, diagnostic yield and completion rate (90-96). To date, 4 meta-analyses have concluded that the ingestion of 2 liters of PEG solution prior to capsule leads to improved visibility of the SB mucosa. However, the evidence relating to completion rates and diagnostic yield is still inconclusive and the optimal timing for purgative use is yet to be established (97-101). The only pediatric RCT, (102) recommends bowel-cleansing with $25 \mathrm{~mL} / \mathrm{kg}$ PEG-solution (up to $1 \mathrm{~L}$ ) the evening before the examination with an overnight fast and subsequent $20 \mathrm{~mL}$ oral simethicone just before ingestion/application, as this resulted in the best visualization score. The same protocol has been recently endorsed by both NASPGHAN and ESGE (103). Other standard IC cleansing regimes are probably just as effective, although simethicone is recommended to decrease bubble artifact.

\section{Capsule Endoscopy Scoring System}

Recent adult guidelines recommend the use of validated endoscopic scoring indices for the assessment of small-bowel inflammatory activity in patients with CD undergoing CE (78). These scores aim to standardize the description of lesions in CE reports, hence increasing inter-observer agreement and providing a reproducible method for assessment of endoscopic activity that could be used to stratify disease severity, guide the decision in the appropriate medical management to monitor the response to therapy and evaluate $\mathrm{MH}$ in SB $(78,104,105)$. Nevertheless, these scoring systems results are not diagnostic due to the lack of specificity of the evaluated parameters and should instead be integrated in the appropriate clinical context $(41,78)$. LS and CE Crohn's Disease Activity Index (CECDAI) are the 2 validated scores currently available to assess inflammatory changes in small-bowel mucosa (104,106-109). Few studies have compared both scores (97), and the majority of literature references the LS. For this reason, the LS may be used for diagnosis in clinical practice, staging, follow-up and therapeutic assessment of pediatric patients with SB CD. A score $<135$ is designated normal or clinically insignificant mucosal inflammatory change, a score between 135 and 790 is mild and a score $>790$ is moderate to severe $(104,107,109,110)$.

\section{Enteroscopy}

Enteroscopy (ES) is mainly used in adult patients, although some pediatric studies report diagnostic yield and safety in selected patients with suspected CD $(111-112)$. Large prospective studies 
are necessary to identify the role of ES in the diagnostic algorithm of IBD in children. Certainly CE may be complemented by tissue acquisition by ES, although for simple diagnostic purposes $\mathrm{CE}$ is the first line investigation. ES should not be used as an initial SB diagnostic test for suspected IBD unless significant small intestinal strictures, which are present that would be a contraindication to $\mathrm{CE}$ use. No validated ES scores have been developed for diagnosis or assessment of severity of SB CD. Firm evidence of the role of ES in IBDU is lacking (113).

ES is indicated to obtain mid small intestinal biopsies, to perform therapeutic procedures such as balloon dilation of stenosis, or when a suspected obstruction or narrowing prevents application of CE. Pediatric endoscopists are gaining experience with this technique. However, in some centers ES is still performed by adult practitioners (114), who should be fully educated in specific aspects of pediatric IBD. In general, the decision whether to perform CE or ES in pediatric IBD may depend on local availability and expertise (113). Nonetheless, due to its lesser invasiveness, CE is usually preferable in the absence of strictures. General considerations specific to ES procedures in children (eg, age limitations, GA, instrument(s) employed) should be considered when deciding whether or not to perform this procedure. ES is safe in both adults and children; however, it is associated with higher risk compared to $\mathrm{CE}$ (115-119). CE findings may help direct the most effective route of ES intubation (oral vs anal), although both approaches may be required $(120-122)$.

\section{THERAPEUTIC ENDOSCOPY Recommendations:}

(1) Endoscopic balloon dilation is suggested in short $(\leq 4 \mathrm{~cm})$ and reachable strictures. [adult EL2, pediatric EL3 RGC]. (82\% agreement)

\section{Practice points:}

(2) In case of longer $(>4 \mathrm{~cm})$, primary, and/or multiple strictures, it is recommended to avoid endoscopic balloon dilations (EBDs) due to the higher risk of complications and lower success rate

(3) Before $\mathrm{EBD}$, it is recommended to characterize the number, nature (inflammatory vs fibrotic) and length of the strictures by using MRE or small intestine contrast ultrasonography.

(4) It is suggested to refer patients to surgery (resection/ strictureplasty) or EBD taking into account the procedural expertise of the endoscopist, patient preference, the probability of success, and the specific nature of the stricture.

(5) In presence of fistulizing disease and abscesses at or adjacent to the site of the procedure, EBD is not recommended due to the increased risk of perforation.

(6) Using intra-lesional injections of corticosteroids or infliximab during endoscopic balloon dilatation or intra-luminal stents is not recommended due to insufficient evidence.

Approximately $50 \%$ of patients with $\mathrm{CD}$ will require surgical intervention within 10 years from initial diagnosis, primarily due to stricturing and penetrating complications (123-125). Stricturing disease has been demonstrated to be an independent risk for the need of surgery with a cumulative risk of $64 \%$ after 10 years (126). In CD, strictures are typically found in the TI, colon and in surgical anastomoses (127). Even though intestinal strictures are not as common in pediatric CD as in adult $\mathrm{CD}$, these are still a major cause of morbidity and one of the leading causes for surgery with a cumulative incidence of $20 \%$ 10 years after diagnosis (128). In general, the term "Therapeutic
Endoscopy" in IBD refers to endoscopic dilatation or stenting of strictures in CD. It is widely accepted that the treatment of choice for permanent non-inflammatory fibro-stenotic strictures in $\mathrm{CD}$, surgery is most commonly a limited ileo-colonic resection (129) with surgical strictureplasty as an alternative approach to preserve bowel length (130). Few pediatric reports are available regarding post-operative recurrence rate (131). Adult-based literature indicates a high rate of recurrence resulting in reoperation $(123,132)$. Over the last 20 years, EBD has emerged as a safe and effective alternative to surgery in adult $\mathrm{CD}$, particularly in cases of ileocecal and anastamotic strictures (133-158). Immediate technical success of EBD defined as the ability to pass through the stricture with the scope, varies between $86 \%$ and $94 \%$ in different series $(133,157)$. The cumulative long-term success defined as surgeryfree rates following EBD ranges between $83 \%$ and $87 \%, 58 \%$ and $72 \%$, and $64 \%$ and $58 \%$ at 1,3 , and 5 years, respectively (133158). In the only published pediatric study (159) describing 29 patients undergoing EBD, a 1-year surgical rate was reported as $14 \%$, in concordance with adult data. Stricture recurrence rates of strictures requiring re-dilatation following EBD are reported to be $20 \%$ to $30 \%, 50 \%$ to $60 \%$, and up to $70 \%$ at 1,3 , and 5 years, respectively $(136,138,142,154,157)$. With the lack of controlled trials comparing EBD to surgical techniques, insufficient evidence exists to conclude whether these rates are comparable to post-surgical recurrence that is reported as $45 \%$ at 5 years (153). Median time for surgery and re-dilation following EBD in patients with recurrent strictures has been reported as 12.8 to 14.5 and 14 months, respectively $(156,157)$.

Surgery-free outcome is reported to be the highest when stricture length is $<4 \mathrm{~cm}$ and when EBD is performed for anastomotic strictures $(133,145,146,150)$. It is not clear whether outcome is affected by factors such as concurrent medical therapy, smoking status and disease activity $(151,156,160,161)$, even though smoking was suggested as a risk factor for recurrence $(143,160)$. Nevertheless, longer $\mathrm{CD}$ duration and higher $\mathrm{C}$-reactive protein levels are reported to be associated with an increased need for subsequent surgery following EBD (159). It is also not clear whether recurrence rates differ between primary and anastomotic strictures $(155,161)$. Two recent studies show a significantly lower long-term success rate in patients with a primary stricture of the ileocecal valve or the terminal ileum $(145,157)$. The presence of a stricture on the ileocecal level was reported as a negative predictive value in the long term with a higher rate of surgery (154).

The reported complication rate, including bowel perforation and significant bleeding (133), is approximately 2\% for EBD compared with a $5 \%$ complication rate in strictureplasty (153). The presence of fistulizing disease and abscesses at or adjacent to the site of procedure are considered contraindications to EBD since both are believed to increase the risk of perforation (132).

Procedural aspects including balloon caliber, duration and number of dilatations required are variable (132), although most studies used a caliber of up to $18 \mathrm{~mm}$ with a maximal caliber of $25 \mathrm{~mm}$. A recent study shows excellent results with balloons used for dilatation up to $18 \mathrm{~mm}$, no more than 90 seconds of insufflation time, and no more than 6 dilatations per session (156). It seems that the risk of more complications is increased when using larger balloons (>20 mm) (141).

Intra-lesional injection of infliximab $(162,163)$ or steroids $(159,164-167)$ to improve the long-term efficacy of EBD has been reported and reveal variable results. In the only pediatric study using EBD published to-date (159), 29 patients were randomized to receive intrastricture injection of corticosteroid or placebo after EBD. The 2 groups statistically differed in the time free of redilatations and for time free of surgery after EBD, which were worse in the placebo group (159). One report suggests that 
postdilation topical application of the anti-fibrotic Mitomycin $\mathrm{C}$ may be of value; however, this needs further verification (168).

Only a few uncontrolled studies report on intraluminal stents for adult $C D$ with no control groups (169-172). The current evidence is not strong enough to support recommendations for using stents for pediatric CD strictures.

In UC, following ileal-pouch anal anastomosis, mechanical, inflammatory and function complications can occur. One of the mechanical complications is the ileal-pouch stricture, which has been reported in $10 \%$ to $40 \%$ of cases (173). Two common locations prone to develop strictures are (1) the pouch-anal anastomosis (pouch outlet) and pouch inlet at the junction of the neo-terminal ileum, and (2) within the pouch. Management of the pouch strictures, especially inlet stricture, can be challenging. Limited data regarding endoscopic management of pouch strictures are available, although EBD is evolving as a comparably effective alternative to surgical strictureplasty in adults (174). Preliminary evidence suggests similar complication rates but with higher recurrence rate following EBD (174). Currently, no scientific evidence supports the use of EBD in ileal-pouch strictures in children.

\section{CANCER SURVEILLANCE}

\section{Recommendations:}

(1) A surveillance program is suggested in pediatric UC after 10 years from the onset of disease. Surveillance may start as early as 8 years in older children ( $>16$ years) if any of the following risk factors are present: extensive colitis; high burden of the colitis over time (a factor of severity and chronicity); and family history of colorectal cancer in a firstdegree relative at $<50$ years [EL5, adults EL2; RGC]. (85\% agreement)

(2) In IBD cases with concurrent primary sclerosing cholangitis (PSC), surveillance IC may be considered annually or at least bi-annually, starting from the time of PSC diagnosis or shortly thereafter. In children $<12$ years of age, surveillance could, however, be postponed depending on to the presence of individual risk factors (disease duration, family history, severity of the disease over time and disease extent) [EL4; RGC]. (90\% agreement)

(3) The endoscopic procedure for surveillance examination should be performed in a quiescent period of the disease to minimize false positive interpretation of dysplasia [EL4; RGC]. (95\% agreement)

\section{Practice points:}

The screening program should be performed by an experienced pediatric or adult gastrointestinal endoscopist.

(1) Surveillance intervals should be individualized according to a risk stratification (extensive colitis; high burden of the colitis over time; and family history of colorectal cancer): annually in those at high risk ( $>2$ factors); every 3 years in those with an intermediate risk ( $>1$ factor); and every 5 years in those without any risk factors.

(2) The combination of high definition (HD) IC and/or chromoendoscopy with indigo carmine or methylene blue spraying is recommended for performing surveillance when possible, otherwise, Narrow Band Imaging (NBI) can also be used. Chromoendoscopy can help target discrete macroscopic lesions.

(3) Confocal laser endomicroscopy (CLE) may have a role in characterizing lesions identified during surveillance.

(4) When HD endoscopy or chromoendoscopy is not available, a high number of random biopsies along the entire colon (2-4 biopsies of 4 segments each $10 \mathrm{~cm}$ ) should be obtained. Extra biopsies can be obtained from strictured, raised, or colorchanged areas in the colorectal mucosa.

Recommendations for endoscopic surveillance for colorectal cancer (CRC) to date include variables, such as starting time of the program, interval of colonoscopies, best endoscopic technique and management of the mucosal abnormalities detected can vary.

It is widely agreed that surveillance IC should be recommended 8 years after diagnosis, thus pediatric gastroenterologists may still be involved since many patients in the pediatric age range experience an early disease onset (26).

Individuals who have had a long-standing history of colonic IBD have an increased risk of developing colorectal cancer (CRC) compared with the general population. Moreover, a recent pediatric report demonstrated that this risk is higher even for other type of cancers (175).

A longer duration of colitis seems to increase the risk of IBDassociated CRC; previous data show a cumulative rate of $1.6 \%$, $8.3 \%$, and $18.4 \%$ at $10,20,30$ years, respectively (176). Recent reports indicate a decline in this rate to $2.5 \%, 7.6 \%$, and $10.8 \%$ at 20, 30 and 40 years, respectively (177). Lakatos et al reported a cumulative risk of $0.6 \%, 5.4 \%$, and $7.5 \%$ at 10,20 , and 30 years in a Hungarian IBD population (178). Interestingly, the incidence rate of CRC in UC seems to be declining, that is, 2-to-3 times higher than that of the general population (179). It is tempting to suggest that optimizing inflammation-suppressing therapy and endoscopic surveillance could explain this reduced incidence.

Other independent risk factors for CRC include the extent and severity of mucosal inflammation. Ekbom et al reported a standardized incidence ratio (SIR) for CRC of 1.7 for proctitis, 2.8 for left-sided disease and 14.8 for pancolitis (180), whereas Soderlund et al documented SIR of 1.7 for proctitis and 5.6 for pancolitis (181). In a case-control study, Rutter et al found a significant correlation between disease severity and cancer risk (OR of 2.5 for colonoscopic and OR of 5.1 for histological inflammation) (182). Postinflammatory polyps are a marker of inflammation and are therefore also associated with an increased CRC risk. Family history of CRC will also increase risk (by 2-3-fold) (183). A meta-analysis suggests that PSC is a further independent risk factor for IBD-associated CRC with an OR of 4.04 when compared with UC without PSC (184).

Patients with PSC and UC have a greater risk of malignancies, such as colorectal cancer and cholangiocarcinoma (8\%-30\% of UC patients with long-standing PSC) $(185,186)$. A recent European study on cancer and mortality in children has demonstrated many cases associated with PSC (187). PSC is associated with more extensive disease, thus predisposing to greater cancer risk (188) even though the disease course of the colitis is milder when associated with PSC. The higher colectomy rate in these patients is secondary to dysplasia and CRC. Older age at PSC diagnosis increases the risk of colonic neoplasia (188).

Childhood age at diagnosis of colitis may be an independent risk factor for IBD-associated CRC. In a meta-analysis, Eaden et al reported on 5 studies with pediatric follow-up data (177). The average age of onset of UC was 10 years and mean duration of follow-up was 12 years. The overall incidence of CRC for any child was $6 / 1000$ person years duration (pyd). The cumulative probability of any child developing cancer was $5.5 \%, 10.8 \%$, and $15.7 \%$ at 10 , 20 , and 30 years, respectively. Ekbom et al also found young age to be associated with an increased risk of developing CRC (180). When adjusted for disease extent, they calculated an SIR of 0.51 with each increase in age group. This age association has, however, not been consistently found. For example, Rutter et al found risk to increase with age of onset $(177,178,189,190)$. 
Although the pediatric phenotype is often characterized by extensive and severe disease and the younger age is associated with increased risk of CRC, only a few childhood-onset CRCs associated with IBD have been reported $(181-183,191)$. de Ridder et al recently conducted a multinational-based survey of cancer and mortality in pediatric IBD on behalf of the ESPGHAN Porto Working Group. Among 18 cases with a diagnosis of cancer under the age of 19, colonic adenocarcinoma was reported only in 1, a boy diagnosed with UC at 3 years who subsequently developed cancer at 16 years (187).

The paucity of pediatric CRCs is consistent with the findings of a recent systematic review of the natural history of pediatric onset IBD (191). Only 1 CRC was reported in the pediatric age group, a 15 -year old child, 3 years after a diagnosis of UC (192). In the other cases, cancer developed in adulthood (193-197). A recent population-based study of the EPIMAD registry, including 698 children with IBD $(529 \mathrm{CD})$ followed for a median of 11.5 years, documented 9 cancer cases (2 CRCs) (198). None of the colon cancers, however, presented in childhood. For all these factors, it seems reasonable to consider a surveillance program in children after 10 years from diagnosis. In cases that include a history of extensive and untreatable colitis over time (a factor of severity and chronicity) and with a family history of colorectal cancer in a first-degree relative at $<50$ years, the surveillance program may be considered after 8 years from diagnosis in older children $(>16$ years) with the same adult protocol (26).

The endoscopy program of surveillance has significantly decreased the incidence of CRC in IBD mainly with the advent of novel techniques $(199,200)$.

Macroscopic abnormalities of colonic mucosa of IBD patients are not readily detected in cases of dysplasia, but rather is found primarily in flat dysplasia. Careful examination may sometimes reveal slight modifications of the submucosal vessels, an achromic plaque or an erythematous area with a granular appearance, nodules or a pseudovillous appearance $(201,202)$.

Dysplasia-associated lesions or masses (DALM) are raised lesions that can be seen as irregular mucosal surface, nodules, or sessile or more rarely, pedunculated polyps $(203,204)$. The latter are difficult to distinguish from either inflammatory pseudopolyps or sporadic colonic adenomas.

Globally, the sensitivity of dysplasia detection is reported to be between $20 \%$ and $72 \%(205,206)$. As the most frequent dysplastic lesions during IBD are almost invisible, adult guidelines recommend performing a high number of random biopsies along the entire colon (207). Extra biopsies can be obtained from strictured, raised, or color-changed areas in the colorectal mucosa (177,208-212). However, this method can be time consuming and laborious.

Different chromoendoscopy techniques have been developed, using indigo carmine or methylene blue coloration of the colon by endoscopic spraying to improve sensitivity $(211,213,214)$. Indigo carmine is a superficial contrast that reveals slight modifications of the mucosa surface, while methylene blue is massively absorbed by normal mucosal, which does not color inflammatory and dysplastic areas. Using these mucosal dyes, analysis of the pit pattern is easier, allowing differentiation of a dysplasic lesion from normal mucosa with a sensitivity and specificity of approximately $90 \%(214,215)$.

Chromoendoscopic analysis can also be performed using new endoscopic techniques, which aim at visualizing detailed surface architecture of the mucosa, vascular patterns, and even the cellular and subcellular structures in real time. Precise observation and targeted biopsy are possible with the progress of novel technologies, with HD endoscopy evolving into the standard tool that is widely used in clinical practice and is often combined with chromoendoscopy or NBI. More sophisticated imaging techniques such as CLE are widely used, but experience is limited to a few documented reports and centers. Only 1 study reports the application of CLE in children (216); most data come from adult literature $(217,218)$.

Although NBI and focused chromoendoscopy increase the detection rate of high-grade dysplasia among sporadic adenomas (219), these optical chromoendoscopy techniques are less accurate than dye-based chromoendoscopy to diagnose IBD-associated dysplasia (220).

At the histological level, dysplasia is defined as an epithelial neoplasia with no invasion of the lamina propria (221), defined by histopathology as indefinite, low and high dysplasia (222).

No clear evidence exists to suggest that endoscopic surveillance of dysplasia decreases mortality due to CRC in IBD patients, even if carcinomas are detected at an earlier stage $(180,222)$.

The frequency of endoscopic surveillance is not clearly defined. Recently it has been suggested that two-thirds of IBDassociated CRC cases can arise from an insufficient surveillance strategy, including poor bowel preparation and inadequacy of both surveillance interval and dysplasia management (223). Considering the lack of sufficient experience in this field, pediatricians should plan and perform the screening program together with an endoscopy surveillance expert.

\section{CONCLUSIONS AND FUTURE PERSPECTIVES}

Endoscopic techniques will be increasingly utilized in the management of pediatric IBD in the near future, particularly with the advent of "tight control" of the disease transforming our concept of therapeutic targets (224). For this reason, the use of new and non-invasive technologies is increasing over the time. Colon capsule endoscopy (CCE) is a novel technique to examine the colon (225). The application of colon capsule in the assessment of pediatric IBD is yet to be determined. An initial report is promising with a high specificity $(100 \%)$ and sensitivity $(96 \%)$ compared with IC (226). However, this contrasts with lower diagnostic yields in adult IBD studies $(227,228)$. Bowel cleansing and a small risk of retention are the possible drawbacks (227). Despite these limitations, CCE offers another option to examine the pediatric large bowel where IC cannot be completed, except in the presence of strictures.

Although CCE is primarily aimed at the assessment of the colon, images of the entire GI tract can be obtained. This has prompted interest in establishing its potential for pan-intestinal endoscopy (229-230). Recently, CCE has proven to be effective in evaluating both SB and colon in pediatric CD in compared with other imaging modalities and standard IC. CCE allows assessment of the entire GI tract with a high diagnostic accuracy (sensitivity of $89 \%$ and specificity of $92 \%$ ) (231). Hence, CCE may be considered as a noninvasive means to evaluate both SB and colon as "onestep" device. The combined CCE may also alter the monitoring of pediatric IBD, with the potential benefit to reduce costs and the need for anesthesia.

Based on these emerging data on the usefulness of panenteric endoscopy for monitoring IBD, a SB and colon (SBC) capsule was designed to image the SB and colon, replacing multiple diagnostic procedures in CD patient management without sedation. The SBC capsule is similar to the CCE in all its hardware components, although it differs in its operational mode and is specifically designed to provide complete coverage of the SB in addition to the colon. Preliminary data in 66 adult $C D$ suggest that the diagnostic yield for SBC may be higher compared with standard IC (83.3\% vs $69.7 \%$, respectively). Further prospective studies are, however, needed to corroborate these data, especially in pediatrics. 
The advent of these non-invasive technologies may change techniques to monitor IBD activity. Indeed, a recent pediatric study confirmed the ability of CCE in guiding therapy in a treat-to-target strategy of pediatric IBD, demonstrating a significant increase of $\mathrm{MH}$ and deep remission rate (232).

The challenge to use more minimally invasive endodiagnostic tools in children will be maintained going forward (233). Use of these tools will be weighed against their lack of tissue histology (59).

Endoscopy in pediatric IBD provides a more definitive diagnosis and disease extent evaluation, assesses therapeutic efficacy and leads to a targeted therapy, which lessens complications and progression. Future studies will confirm these goals and help establish the best time-points and modalities for the application of endoscopy in a treat-to-target strategy of IBD in children, adolescents, and young adults.

\section{REFERENCES}

1. Thomson M, Tringali A, Landi R, et al. Pediatric Gastrointestinal Endoscopy: European Society of Pediatric Gastroenterology Hepatology and Nutrition (ESPGHAN) and European Society of Gastrointestinal Endoscopy (ESGE) Guidelines. J Pediatr Gastroenterol Nutr 2017;64:133-53.

2. Levine A, Koletzko S, Turner D, et al. ESPGHAN Revised Porto criteria for the diagnosis of inflammatory bowel disease in children and adolescents. J Pediatr Gastroenterol Nutr 2014;58:795-806.

3. Shaoul R, Karban A, Reif S, et al. Disease behavior in children with Crohn's disease: the effect of disease duration, ethnicity, genotype, and phenotype. Dig Dis Sci 2009;54:142-50.

4. de Bie CI, Buderus S, Sandhu BK, et al., EUROKIDS Porto IBD Working Group of ESPGHAN. Diagnostic workup of paediatric patients with inflammatory bowel disease in Europe: results of a 5year audit of the EUROKIDS registry. $J$ Pediatr Gastroenterol Nutr 2012;54:374-80.

5. Holtman GA, Lisman-van Leeuwen Y, Day AS, et al. Use of laboratory markers in addition to symptoms for diagnosis of inflammatory bowel disease in children: a meta-analysis of individual patient data. JAMA Pediatr 2017;171:984-91.

6. Hummel TZ, ten Kate FJ, Reitsma JB, et al. Additional value of upper GI tract endoscopy in the diagnostic assessment of childhood IBD. $J$ Pediatr Gastroenterol Nutr 2012;54:753-7.

7. Kovacs M, Muller KE, Arato A, et al., Hungarian IBD Registry Group (HUPIR). Diagnostic yield of upper endoscopy in paediatric patients with Crohn's disease and ulcerative colitis. Subanalysis of the HUPIR registry. J Crohns Colitis 2012;6:86-94.

8. Magro F, Langner C, Driessen A, et al. European consensus on the histopathology of inflammatory bowel disease. J Crohns Colitis 2013;7:827-51.

9. Thakkar K, Lucia CJ, Ferry GD, et al. Repeat endoscopy affects patient management in pediatric inflammatory bowel disease. Am J Gastroenterol 2009;104:722-7.

10. Ho GT, Mowat C, Goddard CJ, et al. Predicting the outcome of severe ulcerative colitis: development of a novel risk score to aid early selection of patients for second-line medical therapy or surgery. Aliment Pharmacol Ther 2004;19:1079-87.

11. Schechter A, Griffiths C, Gana JC, et al. Early endoscopic, laboratory and clinical predictors of poor disease course in paediatric ulcerative colitis. Gut 2015;64:580-8.

12. Turner D, Griffiths AM, Veerman G, et al. Endoscopic and clinical variables that predict sustained remission in children with ulcerative colitis treated with infliximab. Clin Gastroenterol Hepatol 2013;11:1460-5.

13. Ashorn S, Honkanen T, Kolho KL, et al. Fecal calprotectin levels and serological responses to microbial antigens among children and adolescents with inflammatory bowel disease. Inflamm Bowel Dis 2009;15:199-205.

14. Bunn SK, Bisset WM, Main MJ, et al. Fecal calprotectin: validation as a noninvasive measure of bowel inflammation in childhood inflammatory bowel disease. J Pediatr Gastroenterol Nutr 2001;33:14-22.
15. Hanai H, Takeuchi K, Iida, et al. Relationship between fecal calprotectin, intestinal inflammation, and peripheral blood neutrophils in patients with active ulcerative colitis. Dig Dis Sci 2004;49:1438-43.

16. Røseth AG, Aadland E, Jahnsen J, et al. Assessment of disease activity in ulcerative colitis by faecal calprotectin, a novel granulocyte marker protein. Digestion 1997;58:176-80.

17. D'Haens G, Ferrante M, Vermeire S, et al. Fecal calprotectin is a surrogate marker for endoscopic lesions in inflammatory bowel disease. Inflamm Bowel Dis 2012;18:2218-24.

18. Turner D, Levine A, Escher JC, et al. Management of pediatric ulcerative colitis: joint ECCO and ESPGHAN evidence-based consensus guidelines. J Pediatr Gastroenterol Nutr 2012;55:340-61.

19. Issa M, Vijayapal A, Graham MB, et al. Impact of Clostridium difficile on inflammatory bowel disease. Clin Gastroenterol Hepatol 2007;5: $345-51$.

20. Rahier JF, Magro F, Abreu C, et al. Second European evidence-based consensus on the prevention, diagnosis and management of opportunistic infections in inflammatory bowel disease. J Crohns Colitis 2014;8:443-68.

21. Turner D, Mack D, Leleiko N, et al. Severe pediatric ulcerative colitis: a prospective multicenter study of outcomes and predictors of response. Gastroenterology 2010;138:2282-91.

22. Turner D, Travis SP, Griffiths AM, et al. Consensus for managing acute severe ulcerative colitis in children: a systematic review and joint statement from ECCO, ESPGHAN, and the Porto IBD Working Group of ESPGHAN. Am J Gastroenterol 2011;106:574-88.

23. Shen B, Achkar JP, Lashner BA, et al. Irritable pouch syndrome: a new category of diagnosis for symptomatic patients with ileal pouch-anal anastomosis. Am J Gastroenterol 2002;97:972-7.

24. De Cruz P, Kamm MA, Hamilton AL, et al. Crohn's disease management after intestinal resection: a randomised trial. Lancet 2015;385:1406-17.

25. Rutgeerts P, Geboes K, Vantrappen G, et al. Natural history of recurrent Crohn's disease at the ileocolonic anastomosis after curative surgery. Gut 1984;25:665-72.

26. Annese V, Daperno M, Rutter MD, et al. European evidence based consensus for endoscopy in inflammatory bowel disease. J Crohns Colitis 2013;7:982-1018.

27. Dulai PS, Levesque BG, Feagan BG, et al. Assessment of mucosal healing in inflammatory bowel disease: review. Gastrointest Endosc 2015;82:246-55.

28. Samaan MA, Mosli MH, Sandborn WJ, et al. A systematic review of the measurement of endoscopic healing in ulcerative colitis clinical trials: recommendations and implications for future research. Inflamm Bowel Dis 2014;20:1465-71.

29. Khanna R, Khanna R, Bouguen G, et al. A systematic review of measurement of endoscopic disease activity and mucosal healing in Crohn's disease: recommendations for clinical trial design. Inflamm Bowel Dis 2014;20:1850-61.

30. Mazzuoli S, Guglielmi FW, Antonelli E, et al. Definition and evaluation of mucosal healing in clinical practice. Dig Liver Dis 2013;45:969-77.

31. Schroeder KW, Tremaine WJ, Ilstrup DM. Coated oral 5-aminosalicylic acid therapy for mildly to moderately active ulcerative colitis. A randomized study. $N$ Engl J Med 1987;317:1625-9.

32. Travis SP, Schnell D, Krzeski P, et al. Developing an instrument to assess the endoscopic severity of ulcerative colitis: the Ulcerative Colitis Endoscopic Index of Severity (UCEIS). Gut 2012;61:535-42.

33. Samuel S, Bruining DH, Loftus EV Jr et al. Validation of the ulcerative colitis colonoscopic index of severity and its correlation with disease activity measures. Clin Gastroenterol Hepatol 2013;11:49-54.

34. Vuitton L, Peyrin-Biroulet L, Colombel JF, et al. Defining endoscopic response and remission in ulcerative colitis clinical trials: an international consensus. Aliment Pharmacol Ther 2017;45:801-13.

35. Thia KT, Loftus EV Jr, Pardi DS, et al. Measurement of disease activity in ulcerative colitis: interobserver agreement and predictors of severity. Inflamm Bowel Dis 2011;17:1257-64.

36. Mary JY, Modigliani R. Development and validation of an endoscopic index of the severity for Crohn's disease: a prospective multicentre study. Groupe d'Etudes Therapeutiques des Affections Inflammatoires du Tube Digestif (GETAID). Gut 1989;30:983-9. 
37. Rutgeerts P, Diamond RH, Bala M, et al. Scheduled maintenance treatment with infliximab is superior to episodic treatment for the healing of mucosal ulceration associated with Crohn's disease. Gastrointest Endosc 2006;63:433-42.

38. Sanborn WJ, Feagan BG, Hanauer SB, et al. A review of activity indices and efficacy endpoints for clinical trials of medical therapy in adults with Crohn's disease. Gastroenterolgy 2002;112:512-30.

39. Daperno M, D'Haens G, Van Assche G, et al. Development and validation of a new, simplified endoscopic activity score for Crohn's disease: the SES-CD. Gastrointest Endosc 2004;60:505-12.

40. Rutgeerts P, Geboes K, Vantrappen G, et al. Predictability of the postoperative course of Crohn's disease. Gastroenterology 1990;99: 956-63.

41. Peyrin-Biroulet L, Sandborn W, Sands BE, et al. Selecting Therapeutic Targets in Inflammatory Bowel Disease (STRIDE): determining therapeutic goals for treat-to-target. Am J Gastroenterol 2015;110:1324-38.

42. Ruemmele FM, Hyams JS, Otley A, et al. Outcome measures for clinical trials in paediatric IBD: an evidence-based, expert-driven practical statement paper of the paediatric ECCO committee. Gut 2014;64:438-46.

43. Lichtenstein GR, Ramsey D, Rubin DT, et al. Randomised clinical trial: delayed-release oral mesalazine $4.8 \mathrm{~g} /$ day vs. $2.4 \mathrm{~g} /$ day in endoscopic mucosal healing-ASCEND I and II combined analysis. Aliment Pharmacol Ther 2011;33:672-8.

44. Colombel JF, Sandborn WJ, Reinisch W, et al. Infliximab, azathioprine, or combination therapy for Crohn's disease. $N$ Engl J Med 2010;362:1383-95.

45. Bouguen G, Levesque BG, Pola S, et al. Endoscopic Assessment and treating to target increase the likelihood of mucosal healing in patients with Crohn's disease. Clin Gastroenterol Hepatol 2014;12:878-985.

46. Bouguen G, Levesque BG, Pola S, et al. Feasibility of endoscopic assessment and treating to target to achieve mucosal healing in ulcerative colitis. Inflamm Bowel Dis 201;20:231-9.

47. Walters TD, Kim MO, Denson LA, et al. Increased effectiveness of early therapy with anti-tumor necrosis factor-alpha vs an immunomodulator in children with Crohn's disease. Gastroenterology 2014;146: 383-91.

48. Grover Z, Burgess C, Muir R, et al. Early mucosal healing with exclusive enteral nutrition is associated with improved outcomes in newly diagnosed children with luminal Crohn's disease. J Crohns Colitis 2016;10:1159-64.

49. Papi C, Fascì-Spurio F, Rogai F, et al. Mucosal healing in inflammatory bowel disease: treatment efficacy and predictive factors. Dig Liver Dis 2013;45:978-85.

50. Ananthakrishnan AN, Korzenik JR, Hur C, et al. Can mucosal healing be a cost-effective endpoint for biological therapy in Crohn's disease? A decision analysis. Inflamm Bowel Dis 2013;138:463-8.

51. D'Haens G, Sandborn WJ, Feagan BG, et al. A review of activity indices and efficacy end points for clinical trials of medical therapy in adults with ulcerative colitis. Gastroenterology 2007;132:763-86.

52. Van Limbergen J, Russell RK, Drummond HE, et al. Definition of phenotypic characteristics of childhood-onset inflammatory bowel disease. Gastroenterology 2008;135:1114-22.

53. Dave M, Loftus EV Jr. Mucosal healing in inflammatory bowel disease-a true paradigm of success? Gastroenterol Hepatol (N Y) 2012;8:29-38.

54. Vuitton L, Marteau P, Sandborn WJ, et al. IOIBD technical review on endoscopic indices for Crohn's disease clinical trials. Gut 2016;65:1447-55.

55. Ferrante M, Colombel JF, Sanborn WJ, et al. Validation of endoscopic activity scores in patients with Crohn's disease based on a post hoc analysis of data from SONIC. Gastroenterolgy 2013;145:878-86.

56. Santha SL, Shankar PR, Pan A, et al. Mucosal Healing in clinical practice: a single-center pediatric IBD experience. Inflamm Bowel Dis 2017;23:1447-53.

57. Daperno M, Castiglione F, de Ridder L, et al. Results of the 2nd part Scientific Workshop of the ECCO. II: measures and markers of prediction to achieve, detect, and monitor intestinal healing in inflammatory bowel disease. J Crohns Colitis 2011;5:484-98.

58. Colombel JF, Sanborn WJ, Rutgeers P, et al. Adalimumab for maintenance of clinical response and remission in patients with Crohn's disease: the CHARM trail. Gastroenterology 2007;132:52-65.
59. Panes J, Jairath V, Levesque BG. Advances in use of endoscopy, radiology, and biomarkers to monitor inflammatory bowel diseases. Gastroenterology 2017;152:362-73.

60. Kugathasan S, Denson LA, Walters TD, et al. Prediction of complicated disease course for children newly diagnosed with Crohn's disease: a multicentre inception cohort study. Lancet 2017;389:1710-8.

61. Ruemmele FM, Veres G, Kolho KL, et al. Consensus guidelines of ECCO/ESPGHAN on the medical management of pediatric Crohn's disease. J Crohns Colitis 2014;8:1179-207.

62. Loepke AW, Soriano SG. An assessment of the effects of general anesthetics on developing brain structure and neurocognitive function. Anesth Analg 2008;106:1681-707.

63. Gleich S, Nemergut M, Flick R. Anesthetic-related neurotoxicity in young children: an update. Curr Opin Anaesthesiol 2013;26:340-7.

64. Paule MG, Li M, Allen RR, et al. Ketamine anesthesia during the first week of life can cause long-lasting cognitive deficits in rhesus monkeys. Neurotoxicol Teratol 2011;33:220-30.

65. Zou X, Liu F, Zhang X, et al. Inhalation anesthetic-induced neuronal damage in the developing rhesus monkey. Neurotoxicol Teratol 2011;33:592-7.

66. McCann ME, Soriano SG. General anesthetics in pediatric anesthesia: influences on the developing brain. Curr Drug Targets 2012;13: 944-51.

67. Lei SY, Hache M, Loepke AW. Clinical research into anesthetic neurotoxicity: does anesthesia cause neurological abnormalities in humans? J Neurosurg Anesthesiol 2014;26:349-57.

68. Loepke AW, Hansen TG. Is this your (paediatric patient's) brain on (anaesthetic) drugs?: the search for a potential neurological phenotype of anaesthesia-related neurotoxicity in humans. Eur J Anaesthesiol 2015;32:298-300.

69. Hansen TG. Anesthesia-related neurotoxicity and the developing animal brain is not a significant problem in children. Paediatr Anaesth 2015;25:65-72.

70. Cohen SA. The potential applications of capsule endoscopy in pediatric patients compared with adult patients. Gastroenterol Hepatol 2013;9:92-7.

71. Cohen SA, Gralnek IM, Ephrath H, et al. Capsule endoscopy may reclassify pediatric inflammatory bowel disease: a historical analysis. $J$ Pediatr Gastroenterol Nutr 2008;47:31-6.

72. Di Nardo G, Oliva S, Ferrari F, et al. Usefulness of wireless capsule endoscopy in paediatric inflammatory bowel disease. Dig Liver Dis 2011;43:220-4.

73. Gralnek IM, Cohen SA, Ephrath H, et al. Small bowel capsule endoscopy impacts diagnosis and management of pediatric inflammatory bowel disease: a prospective study. Dig Dis Sci 2012;57:465-71.

74. Aloi M, Di Nardo G, Romano G, et al. Magnetic resonance enterography, small-intestine contrast US, and capsule endoscopy to evaluate the small bowel in pediatric Crohn's disease: a prospective, blinded, comparison study. Gastrointest Endosc 2015;81:420-7.

75. Jensen MD, Nathan T, Rafaelsen SR, et al. Diagnostic accuracy of capsule endoscopy for small bowel Crohn's disease is superior to that of MR enterography or CT enterography. Clin Gastroenterol Hepatol 2011;9:124-30.

76. Toth E, Németh A, Nielsen J, et al. Capsule endoscopy is superior to magnetic resonance enterography for detection of Crohn's lesions in the small bowel. Gut 2011;60:A404.

77. Pica R, Fouraki S, Cassieri C, et al. Small bowel involvement in Crohn's disease: a prospective study comparing wireless capsule endoscopy and magnetic resonance enteroclysis. Gut 2012;61:A398.

78. Pennazio M, Spada C, Eliakim R, et al. Small-bowel capsule endoscopy and device-assisted enteroscopy for diagnosis and treatment of small-bowel disorders: European Society of Gastrointestinal Endoscopy (ESGE) Clinical Guideline. Endoscopy 2015;47:352-76.

79. Greener T, Klang E, Yablecovitch D, et al. The impact of magnetic resonance enterography and capsule endoscopy on the re-classification of disease in patients with known Crohn's disease: a Prospective Israeli IBD Research Nucleus (IIRN) Study. J Crohns Colitis 2016;10: 525-31.

80. Kopylov U, Nemeth A, Koulaouzidis A, et al. Small bowel capsule endoscopy in the management of established Crohn's disease: clinical impact, safety, and correlation with inflammatory biomarkers. Inflamm Bowel Dis 2015;21:93-100. 
81. Hall B, Holleran G, Chin JL, et al. A prospective 52 week mucosal healing assessment of small bowel Crohn's disease as detected by capsule endoscopy. J Crohns Colitis 2014;8:1601-9.

82. Oliva S, Cohen SA, Di Nardo G, et al. Capsule endoscopy in pediatrics: a 10-years journey. World J Gastroenterol 2014;20:16603-8.

83. Cohen SA, Klevens AI. Use of capsule endoscopy in diagnosis and management of pediatric patients, based on meta-analysis. Clin Gastroenterol Hepatol 2011;9:490-6.

84. Panes J, Bouhnik Y, Reinisch W, et al. Imaging techniques for assessment of inflammatory bowel disease: joint ECCO and ESGAR evidence- based consensus guidelines. J Crohns Colitis 2013;7: 556-85.

85. Herrerias JM, Leighton JA, Costamagna G, et al. Agile patency system eliminates risk of capsule retention in patients with known intestinal strictures who undergo capsule endoscopy. Gastrointest Endosc 2008;67:902-9.

86. Cohen SA, Ephrath H, Lewis JD, et al. Pediatric capsule endoscopy: a single center, 5 year retrospective review of the small bowel and patency capsules. J Pediatr Gastroenterol Nutr 2012;54:409-13.

87. Rozendorn N, Klang E, Lahat A, et al. Prediction of patency capsule retention in known Crohn's disease patients by using magnetic resonance imaging. Gastrointest Endosc 2016;83:182-7.

88. Fritscher-Ravens A, Scherbakov P, Bufler P, et al. The feasibility of wireless capsule endoscopy in detecting small intestinal pathology in children under the age of 8 years: a multicentre European study. Gut 2009;58:1467-72.

89. Oikawa-Kawamoto M, Sogo T, Yamaguchi T, et al. Safety and utility of capsule endoscopy for infants and young children. World J Gastroenterol 2013;19:8342-8.

90. Viazis N, Sgouros S, Papaxoinis K, et al. Bowel preparation increases the diagnostic yield of capsule endoscopy: a prospective, randomized, controlled study. Gastrointest Endosc 2004;60:534-8.

91. Mergener K, Ponchon T, Gralnek I, et al. Literature review and recommendations for clinical application of small bowel capsule endoscopy, based on a panel discussion by international experts. Consensus statements for small bowel capsule endoscopy, 2006/ 2007. Endoscopy 2007;39:895-909.

92. van Tuyl SA, den Ouden H, Stolk MF, et al. Optimal preparation for video capsule endoscopy: a prospective, randomized, single-blind study. Endoscopy 2007;39:1037-40.

93. Wei W, Ge ZZ, Lu H, et al. Purgative bowel cleansing combined with simethicone improves capsule endoscopy imaging. Am J Gastroenterol 2008; 103:77-82.

94. Wi JH, Moon JS, Choi MG, et al. Bowel preparation for capsule endoscopy: a prospective randomized multicenter study. Gut Liver 2009;3:180-5.

95. Pons Beltran V, Gonzalez Suarez B, Gonzalez Asanza C, et al. Evaluation of different bowel preparations for small bowel capsule endoscopy: a prospective, randomized, controlled study. Dig Dis Sci 2011;56:2900-5.

96. Lapalus MG, Ben Soussan E, Saurin JC, et al. Capsule endoscopy and bowel preparation with oral sodium phosphate: a prospective randomized controlled trial. Gastrointest Endosc 2008;67:1091-6.

97. Park SC, Keum B, Seo YS, et al. Effect of bowel preparation with polyethylene glycol on quality of capsule endoscopy. Dig Dis Sci 2011;56:1769-75.

98. Niv Y. Efficiency of bowel preparation for capsule endoscopy examination: a meta-analysis. World J Gastroenterol 2008;14:1313-7.

99. Rokkas T, Papaxoinis K, Triantafyllou K, et al. Does purgative preparation influence the diagnostic yield of small bowel video capsule endoscopy?: a meta-analysis. Am J Gastroenterol 2009;104: 219-27.

100. Kotwal VS, Attar BM, Gupta S, et al. Should bowel preparation, antifoaming agents, or prokinetics be used before video capsule endoscopy? A systematic review and meta-analysis. Eur J Gastroenterol Hepatol 2014;26:137-45.

101. Wu S, Gao YJ, Ge ZZ. Optimal use of polyethylene glycol for preparation of small bowel video capsule endoscopy: a network meta-analysis. Curr Med Res Opin 2017;33:1149-54.

102. Oliva S, Cucchiara S, Spada C, et al. Small bowel cleansing for capsule endoscopy in paediatric patients: a prospective randomized singleblind study. Dig Liver Dis 2014;46:51-5.
103. Friedlander JA1, Liu QY, Sahn B, et al. NASPGHAN capsule endoscopy clinical report. J Pediatr Gastroenterol Nutr 2017;64:485-94.

104. Cotter J, Dias de Castro F, Magalhães J, et al. Validation of the Lewis score for the evaluation of small-bowel Crohn's disease activity. Endoscopy 2015;47:330-5.

105. Gurudu SR, Leighton JA. Assessment and validation of the new capsule endoscopy Crohn's disease activity index (CECDAI): what difference does it make? Inflamm Bowel Dis 2009;15:1607-8.

106. Niv Y, Ilani S, Levi Z, et al. Validation of the Capsule Endoscopy Crohn's Disease Activity Index (CECDAI or Niv score): a multicenter prospective study. Endoscopy 2012;44:21-6.

107. Gralnek IM, Defranchis R, Seidman E, et al. Development of a capsule endoscopy scoring index for small bowel mucosal inflammatory change. Aliment Pharmacol Ther 2008;27:146-54.

108. Gal E, Geller A, Fraser G, et al. Assessment and validation of the new capsule endoscopy Crohn's disease activity index (CECDAI). Dig Dis Sci 2008;53:1933-7.

109. Rosa B, Moreira MJ, Rebelo A, et al. Lewis Score: a useful clinical tool for patients with suspected Crohn's disease submitted to capsule endoscopy. J Crohns Colitis 2012;6:692-7.

110. Koulaouzidis A, Douglas S, Plevris JN. Lewis score correlates more closely with fecal calprotectin than Capsule Endoscopy Crohn's Disease Activity Index. Dig Dis Sci 2012;57:987-93.

111. Di Nardo G, Oliva S, Aloi M, et al. Usefulness of single-balloon enteroscopy in pediatric Crohn's disease. Gastrointest Endosc 2012;75:80-6

112. de Ridder L, Mensink PB, Lequin MH, et al. Single-balloon enteroscopy, magnetic resonance enterography, and abdominal US useful for evaluation of small-bowel disease in children with (suspected) Crohn's disease. Gastrointest Endosc 2012;75:87-94.

113. Bourreille A, Ignjatovic A, Aabakken L, et al. Role of small-bowel endoscopy in the management of patients with inflammatory bowel disease: an international OMED-ECCO consensus. Endoscopy 2009;41:618-37.

114. Thomson M, Venkatesh K, Elmalik K, et al. Double balloon enteroscopy in children: diagnosis, treatment, and safety. World J Gastroenterol 2010;16:56-62.

115. Davies GR, Benson MJ, Gertner DJ, et al. Diagnostic and therapeutic push type enteroscopy in clinical use. Gut 1995;37:346-52.

116. Darbari A, Kalloo AN, Cuffari C, et al. Diagnostic yield, safety, and efficacy of push enteroscopy in pediatrics. Gastrointest Endosc 2006;64:224-8.

117. Mehdizadeh S, Han NJ, Cheng DW, et al. Success rate of retrograde double-balloon enteroscopy. Gastrointest Endosc 2007;65:633-9.

118. Mehdizadeh S, Ross A, Gerson L, et al. What is the learning curve associated with double-balloon enteroscopy? Technical details and early experience in 6 US tertiary care centers. Gastrointest Endosc 2006;64:740-50.

119. Gerson LB, Tokar J, Chiorean M, et al. Complications associated with double balloon enteroscopy at nine US centers. Clin Gastroenterol Hepatol 2009;7:1177-82.

120. Pasha SF, Leighton JA, Das A, et al. Double-balloon enteroscopy and capsule endoscopy have comparable diagnostic yield in small-bowel disease: a meta-analysis. Clin Gastroenterol Hepatol 2008;6:671-6.

121. Chong AK, Taylor A, Miller A, et al. Capsule endoscopy vs. push enteroscopy and enteroclysis in suspected small-bowel Crohn's disease. Gastrointest Endosc 2005;61:255-61.

122. Wiarda BM, Stolk M, Heine DG, et al. Patient burden and patient preference: comparing magnetic resonance enteroclysis, capsule endoscopy and balloon-assisted enteroscopy. J Gastroenterol Hepatol 2013;28:464-71.

123. Punati J, Markowitz J, Lerer T, et al. Effect of early immunomodulator use in moderate to severe pediatric Crohn disease. Inflamm Bowel Dis 2008;14:949-54.

124. Vernier-Massouille G, Balde M, Salleron J, et al. Natural history of pediatric Crohn's disease: a population-based cohort study. Gastroenterology 2008;135:1106-13.

125. Solberg IC, Vatn MH, Høie O, et al. IBSEN Study Group. Clinical course in Crohn's disease: results of a Norwegian population-based ten-year follow-up study. Clin Gastroenterol Hepatol 2007:5:1430-8.

126. Cosnes J, Cattan S, Blain A, et al. Long-term evolution of disease behavior of Crohn's disease. Inflamm Bowel Dis 2002;8:244-50. 
127. Gupta N, Bostrom AG, Kirschner BS, et al. Incidence of stricturing and penetrating complications of Crohn's disease diagnosed in pediatric patients. Inflamm Bowel Dis 2010;16:638-44.

128. Yamamoto T, Watanabe T. Surgery for luminal Crohn's disease. World J Gastroenterol 2014;20:78-90.

129. Geltzeiler CB, Young JI, Diggs BS, et al. Strictureplasty for treatment of Crohn's disease: an ACS-NSQIP Database Analysis. J Gastrointest Surg 2015;19:905-10.

130. Romeo E, Jasonni V, Caldaro T, et al. Strictureplasty and intestinal resection: different options in complicated pediatric-onset Crohn disease. J Pediatr Surg 2012;47:944-8.

131. Ozuner G, Fazio VW, Lavery IC, et al. Reoperative rates for Crohn's disease following strictureplasty. Long-term analysis. Dis Colon Rectum 1996;39:1199-203.

132. Hassan C, Zullo A, De Francesco V, et al. Systematic review: endoscopic dilatation in Crohn's disease. Aliment Pharmacol Ther 2007;26:1457-64.

133. Singh VV, Draganov P, Valentine J. Efficacy and safety of endoscopic balloon dilation of symptomatic upper and lower gastrointestinal Crohn's disease strictures. J Clin Gastroenterol 2005;39:284-90.

134. Morini S, Hassan C, Lorenzetti R, et al. Long-term outcome of endoscopic pneumatic dilatation in Crohn's disease. Dig Liver Dis 2003;35:893-7.

135. Stienecker K, Gleichmann D, Neumayer U, et al. Long-term results of endoscopic balloon dilatation of lower gastrointestinal tract strictures in Crohn's disease: a prospective study. World $J$ Gastroenterol 2009;15:2623-7.

136. Ajlouni Y, Iser JH, Gibson PR. Endoscopic balloon dilatation of intestinal strictures in Crohn's disease: safe alternative to surgery. $J$ Gastroenterol Hepatol 2007;22:486-90.

137. Foster EN, Quiros JA, Prindiville TP. Long-term follow-up of the endoscopic treatment of strictures in pediatric and adult patients with inflammatory bowel disease. J Clin Gastroenterol 2008;42: $880-5$.

138. Ferlitsch A, Reinisch W, Puspok A, et al. Safety and efficacy of endoscopic balloon dilation for treatment of Crohn's disease strictures. Endoscopy 2006;38:483-7.

139. Sabate JM, Villarejo J, Bouhnik Y, et al. Hydrostatic balloon dilatation of Crohn's strictures. Aliment Pharmacol Ther 2003;18:409-13.

140. Breysem Y, Janssens JF, Coremans G, et al. Endoscopic balloon dilation of colonic and ileo-colonic Crohn's strictures: long-term results. Gastrointest Endosc 1992;38:142-7.

141. Thomas-Gibson S, Brooker JC, et al. Colonoscopic balloon dilation of Crohn's strictures: a review of long-term outcomes. Eur J Gastroenterol Hepatol 2003;15:485-8.

142. Hoffmann JC, Heller F, Faiss S, et al. Through the endoscope balloon dilation of ileocolonic strictures: prognostic factors, complications, and effectiveness. Int J Colorectal Dis 2008;23:689-96.

143. Scimeca D, Mocciaro F, Cottone M, et al. Efficacy and safety of endoscopic balloon dilation of symptomatic intestinal Crohn's disease strictures. Dig Liver Dis 2011;43:121-5.

144. Mueller T, Rieder B, Bechtner G, et al. The response of Crohn's strictures to endoscopic balloon dilation. Aliment Pharmacol Ther 2010;31:634-9.

145. Couckuyt H, Gevers AM, Coremans G, et al. Efficacy and safety of hydrostatic balloon dilatation of ileocolonic Crohn's strictures: a prospective long term analysis. Gut 1995;36:577-80.

146. Gevers AM, Couckuyt H, Coremans G, et al. Efficacy and safety of hydrostatic balloon dilation of ileocolonic Crohn's strictures. A prospective long-term analysis. Acta Gastroenterol Belg 1994;57:320-2.

147. Nomura E, Takagi S, Kikuchi T, et al. Efficacy and safety of endoscopic balloon dilation for Crohn's strictures. Dis Colon Rectum 2006;49(10 suppl):S59-67.

148. Saunders BP, Brown GJ, Lemann M, et al. Balloon dilation of ileocolonic strictures in Crohn's disease. Endoscopy 2004;36:1001-7.

149. Gustavsson A, Magnuson A, Blomberg B, et al. Endoscopic dilation is an efficacious and safe treatment of intestinal strictures in Crohn's disease. Aliment Pharmacol Ther 2012;36:151-8.

150. Thienpont C, D'Hoore A, Vermeire S, et al. Long-term outcome of endoscopic dilatation in patients with Crohn's disease is not affected by disease activity or medical treatment. Gut 2010;59:320-4.
151. Coffey MJ, Wright RA. Efficacy and safety of hydrostatic balloon dilatation of ileocolonic Crohn's studies: a prospective long term analysis. Gastrointest Endosc 1996;43:89-90.

152. Wibmer AG, Kroesen AJ, Grone J, et al. Comparison of strictureplasty and endoscopic balloon dilatation for stricturing Crohn's disease-review of the literature. Int J Colorectal Dis 2010;25:1149-57.

153. Hirai F, Beppu T, Takatsu N, et al. Long-term outcome of endoscopic balloon dilation for small bowel strictures in patients with Crohn's disease. Dig Endosc 2014;26:545-51.

154. de'Angelis N, Carra MC, Borrelli O, et al. Short- and long-term efficacy of endoscopic balloon dilation in Crohn's disease strictures. World J Gastroenterol 2013;19:2660-7.

155. Nanda K, Courtney W, Keegan D, et al. Prolonged avoidance of repeat surgery with endoscopic balloon dilatation of anastomotic strictures in Crohn's disease. J Crohns Colitis 2013;7:474-80.

156. Endo K, Takahashi S, Shiga H, et al. Short and long-term outcomes of endoscopic balloon dilatation for Crohn's disease strictures. World $J$ Gastroenterol 2013;19:86-91.

157. Hagel AF, Hahn A, Dauth W, et al. Outcome and complications of endoscopic balloon dilatations in various types of ileocaecal and colonic stenosis in patients with Crohn's disease. Surg Endosc 2014;28:2966-72.

158. Bhalme M, Sarkar S, Lal S, et al. Endoscopic balloon dilatation of Crohn's disease strictures: results from a large United Kingdom series. Inflamm Bowel Dis 2014;20:265-70.

159. Di Nardo G, Oliva S, Passariello M, et al. Intralesional steroid injection after endoscopic balloon dilation in pediatric Crohn's disease with stricture: a prospective, randomized, double-blind, controlled trial. Gastrointest Endosc 2010;72:1201-8.

160. Gustavsson A, Magnuson A, Blomberg B, et al. Smoking is a risk factor for recurrence of intestinal stricture after endoscopic dilation in Crohn's disease. Aliment Pharmacol Ther 2013;37:430-7.

161. Atreja A, Aggarwal A, Dwivedi S, et al. Safety and efficacy of endoscopic dilation for primary and anastomotic Crohn's disease strictures. J Crohns Colitis 2014;8:392-400.

162. Swaminath A, Lichtiger S. Dilation of colonic strictures by intralesional injection of infliximab in patients with Crohn's colitis. Inflamm Bowel Dis 2008;14:213-6.

163. Hendel J, Karstensen JG, Vilmann P. Serial intralesional injections of infliximab in small bowel Crohn's strictures are feasible and might lower inflammation. United European Gastroenterol J 2014;2:406-12.

164. East JE, Brooker JC, Rutter MD, et al. A pilot study of intrastricture steroid versus placebo injection after balloon dilatation of Crohn's strictures. Clin Gastroenterol Hepatol 2007;5:1065-9.

165. Brooker JC, Beckett CG, Saunders BP, et al. Long-acting steroid injection after endoscopic dilation of anastomotic Crohn's strictures may improve the outcome: a retrospective case series. Endoscopy 2003;35:333-7.

166. Lavy A. Triamcinolone improves outcome in Crohn's disease strictures. Dis Colon Rectum 1997;40:184-6.

167. Van Assche G. Intramural steroid injection and endoscopic dilation for Crohn's disease. Clin Gastroenterol Hepatol 2007;5:1027-8.

168. Rosseneu S, Afzal N, Yerushalmi B, et al. Topical application of mitomycin-C in oesophageal strictures. J Pediatr Gastroenterol Nutr 2007;44:336-41.

169. Matsuhashi N, Nakajima A, Suzuki A, et al. Long-term outcome of non-surgical strictureplasty using metallic stents for intestinal strictures in Crohn's disease. Gastrointest Endosc 2000;51:343-5.

170. Loras C, Perez-Roldan F, Gornals JB, et al. Endoscopic treatment with self-expanding metal stents for Crohn's disease strictures. Aliment Pharmacol Ther 2012;36:833-9.

171. Branche J, Attar A, Vernier-Massouille G, et al. Extractible selfexpandable metal stent in the treatment of Crohn's disease anastomotic strictures. Endoscopy 2012;44(suppl 2):E325-6.

172. Karstensen JG, Vilmann P, Hendel J. Successful endoscopic treatment of a 12-cm small-bowel Crohn stricture with a custom-made biodegradable stent. Endoscopy 2014;46(suppl 1):E227-8.

173. Francone TD, Champagne B. Considerations and complications in patients undergoing ileal pouch anal anastomosis. Surg Clin North Am 2013;93:107-43. 
174. Wu XR, Mukewar S, Kiran RP, et al. Surgical stricturoplasty in the treatment of ileal pouch strictures. J Gastrointest Surg 2013;17: 1452-61.

175. Olen O, Askling J, Sachs MC, et al. Childhood onset inflammatory bowel disease and risk of cancer: a Swedish nationwide cohort study 1964-2014. BMJ 2017;358:j3951.

176. Eaden JA, Abrams KR, Mayberry JF. The risk of colorectal cancer in ulcerative colitis: a meta-analysis. Gut 2001;48:526-35.

177. Rutter M, Saunders B, Wilkinson K, et al. Thirty-year analysis of a colonoscopic surveillance program for neoplasia in ulcerative colitis. Gastroenterology 2006;130:1030-8.

178. Lakatos L, Mester G, Erdelyi Z, et al. Risk factors for ulcerative colitisassociated colorectal cancer in a Hungarian cohort of patients with ulcerative colitis: results of a population-based study. Inflamm Bowel Dis 2006;12:205-11.

179. Bae SI, Kim YS. Colon cancer screening and surveillance in inflammatory bowel disease. Clin Endos 2014;47:509-15.

180. Ekbom A, Helmick C, Zack M, et al. Ulcerative colitis and colorectal cancer. A population -based study. N Engl J Med 1990;323:1228-33.

181. Soderlund S, Brandt L, Lapidus A, et al. Decreasing time-trends of colorectal cancer in a large cohort of patients with inflammatory bowel disease. Gastroenterology 2009;136:1561-7.

182. Rutter M, Saunders B, Wilkinson K, et al. Severity of inflammation is a risk factor for colorectal neoplasm in ulcerative colitis. Gastroenterology 2004;126:451-9.

183. Nuako KW, Ahlquist DA, Mahoney DW, et al. Familial predisposition for colorectal cancer in chronic ulcerative colitis: a case-control study. Gastroenterology 1998;115:1079-83.

184. Soetikno RM, Lin OS, Heidenrich PA, et al. Increased risk of colorectal neoplasia in patients with primary sclerosing cholangitis and ulcerative colitis: a meta-analysis. Gastrointest Endosc 2002;56: 48-54.

185. Broome U, Lofberg R, Veress B, et al. Primary sclerosing cholangitis and ulcerative colitis: evidence for increased neoplastic potential Hepatology 1995;22:1404-8.

186. Fevery J, Henckaerts L, Van Oirbeek R, et al. Malignancies and mortality in 200 patients with primary sclerosering cholangitis: a long-term single-centre study. Liver Int 2012;32:214-22.

187. de Ridder L, Turner D, Wilson DC, et al. Malignancy and mortality in pediatric patients with inflammatory bowel disease: a multinational study from the Porto Pediatric IBD Group. Inflamm Bowel Dis 2014;20:291-300.

188. Navaneethan U, Kochhar G, Venkatesh PG, et al. Duration and severity of primary sclerosing cholangitis is not associated with risk of neoplastic changes in the colon in patients with ulcerative colitis. Gastrointest Endosc 2012;75:1045.e1-54.e1.

189. Jess T, Rungoe C, Peyrin-Biroulet L. Risk of colorectal cancer in patients with ulcerative colitis: a meta-analysis of population based cohort studies. Clin Gastroenterol Hepatol 2012;10:639-45.

190. Bernstein CN, Blanchard JF, Kliewer E, et al. Cancer risk in patients with inflammatory bowel disease: a population based study. Cancer 2001;91:854-62.

191. Abraham BP, Mehta S, El-Serag HB. Natural history of pediatric-onset inflammatory bowel disease. A systematic review. J Clin Gastroenterol 2012;46:581-9.

192. Jakobsen C, Paerregaard A, Munkholm P, et al. Pediatric inflammatory bowel disease during a 44-year period in Copenhagen County: occurrence, course and prognosis-a population-based study from the Danish Crohn Colitis Database. Eur J Gastroenterol Hepatol 2009;21: 1291-301.

193. Gower-Rousseau C, Dauchet L, Vernier-Massouille G, et al. The natural history of pediatric ulcerative colitis: a population-based cohort study. Am J Gastroenterol 2009;104:2080-8.

194. Hyams JS, Davis P, Grancher K, et al. Clinical outcome of ulcerative colitis in children. J Pediatr 1996;129:81-8.

195. Mamula P, Telega GW, Markowitz JE, et al. Inflammatory bowel disease in children 5 years of age and younger. Am J Gastroenterol 2002;97:2005-10.

196. Pigneur B, Seksik P, Viola S, et al. Natural history of Crohn's disease: comparison between childhood- and adult-onset disease. Inflamm Bowel Dis 2010;16:951-61.
197. Langholz E, Munkholm P, Krasilnikoff PA, et al. Inflammatory bowel disease with onset in childhood: clinical features, morbidity, and mortality in a regional cohort. Scand J Gastroenterol 1997;32: 139-47.

198. Peneau A, Savoye G, Tuek D, et al. Mortality and cancer in pediatriconset inflammatory bowel disease: a population-based study. Am J Gastroenterol 2013;108:1647-53.

199. Jess T, Simonsen J, Jørgensen KT, et al. Decreasing risk of colorectal cancer in patients with inflammatory bowel disease over 30 years. Gastroenterology 2012;143:375-81.

200. Cheon JH, Kim WH. Recent advances of endoscopy in inflammatory bowel diseases. Gut Liver 2007;1:118-25.

201. Tytgat GN, Dhir V, Gopinath N. Endoscopic appearance of dysplasia and cancer in inflammatory bowel disease. Eur J Cancer 1995;31: 1174-7.

202. Greenson JK. Dysplasia in inflammatory bowel disease. Semin Diagn Pathol 2002;19:31-7.

203. Rosenstock E, Farmer RG, Petras R, et al. Surveillance for colonic carcinoma in ulcerative colitis. Gastroenterology 1985;89:1342-6.

204. Blackstone MO, Riddell RH, Rogers BH, et al. Dysplasia-associated lesion or mass (DALM) detected by colonoscopy in long-standing ulcerative colitis: an indication for colectomy. Gastroenterology 1981;80:366-74.

205. Jaramillo E, Watanabe M, Slezak P, et al. Flat neoplastic lesions of the colon and rectum detected by high-resolution video endoscopy and chromoscopy. Gastrointest Endosc 1995;42:114-22.

206. Rubin DT, Rothe JA, Hetzel JT, et al. Are dysplasia and colorectal cancer endoscopically visible in patients with ulcerative colitis? Gastrointest Endosc 2007;65:998-1004.

207. Itzkowitz SH, Present DH. Crohn's and Colitis Foundation of America Colon Cancer in IBD Study Group. Consensus conference: colorectal cancer screening and surveillance in inflammatory bowel disease. Inflamm Bowel Dis 2005;11:314-21.

208. Panaccione R. The approach to dysplasia surveillance in inflammatory bowel disease. Can J Gastroenterol 2006;20:251-3.

209. Biancone L, Michetti P, Travis S, et al. European evidence-based consensus on the management of ulcerative colitis: special situations. $J$ Crohns Colitis 2008;2:63-92.

210. Eaden JA, Mayberry JF. British Society for Gastroenterology; Association of Coloproctology for Great Britain and Ireland. Guidelines for screening and surveillance of asymptomatic colorectal cancer in patients with inflammatory bowel disease. Gut 2002;51(suppl 5):V10-2.

211. Kiesslich R, Goetz M, Lammersdorf K, et al. Chromoscopy-guided endomicroscopy increases the diagnostic yield of intraepithelial neoplasia in ulcerative colitis. Gastroenterology 2007;132:874-82.

212. Hlavaty T, Huorka M, Koller T, et al. Colorectal cancer screening in patients with ulcerative and Crohn's colitis with use of colonoscopy, chromoendoscopy and confocal endomicroscopy. Eur J Gastroenterol Hepatol 2011;23:680-9.

213. Kiesslich R, Fritsch J, Holtmann M, et al. Methylene blue-aided chromoendoscopy for the detection of intraepithelial neoplasia and colon cancer in ulcerative colitis. Gastroenterology 2003;124: 880-8.

214. Rutter MD, Saunders BP, Schofield G, et al. Pancolonic indigo carmine dye spraying for the detection of dysplasia in ulcerative colitis. Gut 2004;53:256-60.

215. Hurlstone DP, Sanders DS, Lobo AJ, et al. Indigo carmine-assisted high-magnification chromoscopic colonoscopy for the detection and characterisation of intraepithelial neoplasia in ulcerative colitis: a prospective evaluation. Endoscopy 2005;37:1186-92.

216. Venkatesh K, Cohen M, Evans C, et al. Feasibility of confocal endomicroscopy in the diagnosis of paediatric gastrointestinal disorders. World J Gastroenterol 2009;15:2214-9.

217. Hurlstone DP, Kiesslich R, Thomson M, et al. Confocal chromoscopic endomicroscopy is superior to chromoscopy alone for the detection and characterisation of intraepithelial neoplasia in chronic ulcerative colitis. Gut 2008;57:196-204.

218. Hurlstone DP, Baraza W, Brown S, et al. In vivo real-time confocal laser scanning endomicroscopic colonoscopy for the detection and characterization of colorectal neoplasia. Br J Surg 2008;95:636-45. 
219. Yoshida N. Image-enhanced endoscopy for diagnosis of colorectal tumors in view of endoscopic treatment. World J Gastrointest Endosc 2012;4:545-55.

220. Tontini GE, Vecchi M, Neurath MF, et al. Review article: newer optical and digital chromoendoscopy techniques vs. dye-based chromoendoscopy for diagnosis and surveillance in inflammatory bowel disease. Aliment Pharmacol Ther 2013;38:1198-208.

221. Riddell RH, Goldman H, Ransohoff DF, et al. Dysplasia in inflammatory bowel disease: standardized classification with provisional clinical applications. Hum Pathol 1983;14:931-68.

222. Choi PM, Zelig MP. Similarity of colorectal cancer in Crohn's disease and ulcerative colitis: implications for carcinogenesis and prevention. Gut 1994;35:950-4.

223. Mooiweer E, van der Meulen-de Jong AE, Ponsioen CY, et al. Incidence of interval colorectal cancer among inflammatory bowel disease patients undergoing regular colonoscopic surveillance. Clin Gastroenterol Hepatol 2015;13:1656-61.

224. Colombel JF, Narula N, Peyrin-Biroulet L. Management strategies to improve outcomes of patients with inflammatory bowel diseases. Gastroenterology 2017;152:351-61.

225. Adler DG, Chand B, Conway JD, et al. Capsule endoscopy of the colon. Gastrointest Endosc 2008;68:621-3.

226. Oliva S, Di Nardo G, Hassan C, et al. Second-generation colon capsule endoscopy vs. colonoscopy in pediatric ulcerative colitis: a pilot study. Endoscopy 2014;46:485-92.
227. Meister T, Heinzow HS, Domagk D, et al. Colon capsule endoscopy versus standard colonoscopy in assessing disease activity of ulcerative colitis: a prospective trial. Tech Coloproctol 2013;17: $641-6$.

228. Sung J, Ho KY, Chiu HM, et al. The use of Pillcam Colon in assessing mucosal inflammation in ulcerative colitis: a multicenter study. Endoscopy 2012;44:754-8.

229. Remes-Troche JM, Jiménez-García VA, García-Montes JM, et al. Application of colon capsule endoscopy (CCE) to evaluate the whole gastrointestinal tract: a comparative study of singlecamera and dual-camera analysis. Clin Exp Gastroenterol 2013; 6:185-92.

230. Boal Carvalho P, Rosa B, Dias de Castro F, et al. PillCam COLON 2 in Crohn's disease: a new concept of panenteric mucosal healing assessment. World J Gastroenterol 2015;21:7233-41.

231. Oliva S, Cucchiara S, Civitelli F, et al. Colon capsule endoscopy compared with other modalities in the evaluation of pediatric Crohn's disease of the small bowel and colon. Gastrointest Endosc 2016; 83:975-83.

232. Oliva S, Aloi M, Viola F, et al. A treat-to-target strategy using pan-enteric capsule endoscopy in pediatric crohn's disease. Clinical Gastroenterol Hepatol 2018 [in press].

233. Oliva S, Cucchiara S, Cohen SA. Recent advances in pediatric gastrointestinal endoscopy: an overview. Expert Rev Gastroenterol Hepatol 2017;11:643-50. 